\title{
Technical note: The libRadtran software package for radiative transfer calculations - description and examples of use
}

\author{
B. Mayer ${ }^{1}$ and A. Kylling ${ }^{2,3}$ \\ ${ }^{1}$ Deutsches Zentrum für Luft- und Raumfahrt (DLR), Institut für Physik der Atmosphäre, Oberpfaffenhofen, Germany \\ ${ }^{2}$ St. Olavs Hospital, Trondheim University Hospital, Norway \\ ${ }^{3}$ previously at: Norwegian Institute for Air Research (NILU), Kjeller, Norway
}

Received: 25 November 2004 - Published in Atmos. Chem. Phys. Discuss.: 9 March 2005

Revised: 13 June 2005 - Accepted: 27 June 2005 - Published: 26 July 2005

\begin{abstract}
The libRadtran software package is a suite of tools for radiative transfer calculations in the Earth's atmosphere. Its main tool is the uvspec program. It may be used to compute radiances, irradiances and actinic fluxes in the solar and terrestrial part of the spectrum. The design of uvspec allows simple problems to be easily solved using defaults and included data, hence making it suitable for educational purposes. At the same time the flexibility in how and what input may be specified makes it a powerful and versatile tool for research tasks. The uvspec tool and additional tools included with libRadtran are described and realistic examples of their use are given. The libRadtran software package is available from http://www.libradtran.org.
\end{abstract}

\section{Introduction}

Radiation is the key component of the Earth-atmosphere system. Solar radiation drives atmospheric circulation and hence weather and climate. Tropospheric and stratospheric chemistry are controlled by photochemical reactions and hence by shortwave radiation. Accurate knowledge about solar and terrestrial radiation and their interaction with clouds, aerosol particles, and trace gases is therefore required for a variety of purposes. Radiative transfer models are used to calculate the radiation field for given atmospheric and surface conditions. Applications for radiative transfer calculations include remote sensing, process studies, UV-forecast, radiative forcing, photolysis frequencies, radiative heating/cooling etc. Flexible and versatile tools are required to realistically handle the variety of problems. Here the libRadtran software package for radiative transfer calculations in the Earth's atmosphere is described. The libRadtran package includes numerous tools that may be used to

Correspondence to: $\mathrm{B}$. Mayer

(bernhard.mayer@dlr.de) address various problems related to atmospheric radiation. The main tool is the uvspec radiative transfer model. It will be described first. Secondly, the other libRadtran tools will be summarized followed by examples of usage of the various tools. The description applies to version 1.0 or later of the package.

\section{The uvspec radiative transfer model}

The uvspec radiative transfer model calculates the radiation field in the Earth's atmosphere for a variety of atmospheric conditions. Originally it was designed to calculate spectral irradiance in the ultraviolet and visible parts of the spectrum. Over the years, uvspec has undergone numerous extensions and improvements, including a complete rewrite in 1997 since when the model package has been called libRadtran. Probably the most important change was an extension from the ultraviolet to the complete solar and thermal spectral ranges. The name uvspec is thus outdated, but has been kept for historical reasons. For this reason, uvspec still is the name of the radiative transfer model while libRadtran refers to the complete software package including data sets, tools, examples, and documentation.

The uvspec model is invoked from the command line (similar both for UNIX-like and Windows types of operating systems)

$$
\text { uvspec }<\text { input_file }>\text { output_file }
$$

where the input_file is a free format ASCII file that contains options and corresponding parameters specified by the user. A description of the numerous options (close to 200 for version 1.0) and respective parameters is provided in the libRadtran User's Guide. Some options are described below. They are identified by being written in bold face, for example quiet which takes no parameters and turns off output of a number of informative but not neccessarily required messages,

(C) 2005 Author(s). This work is licensed under a Creative Commons License. 


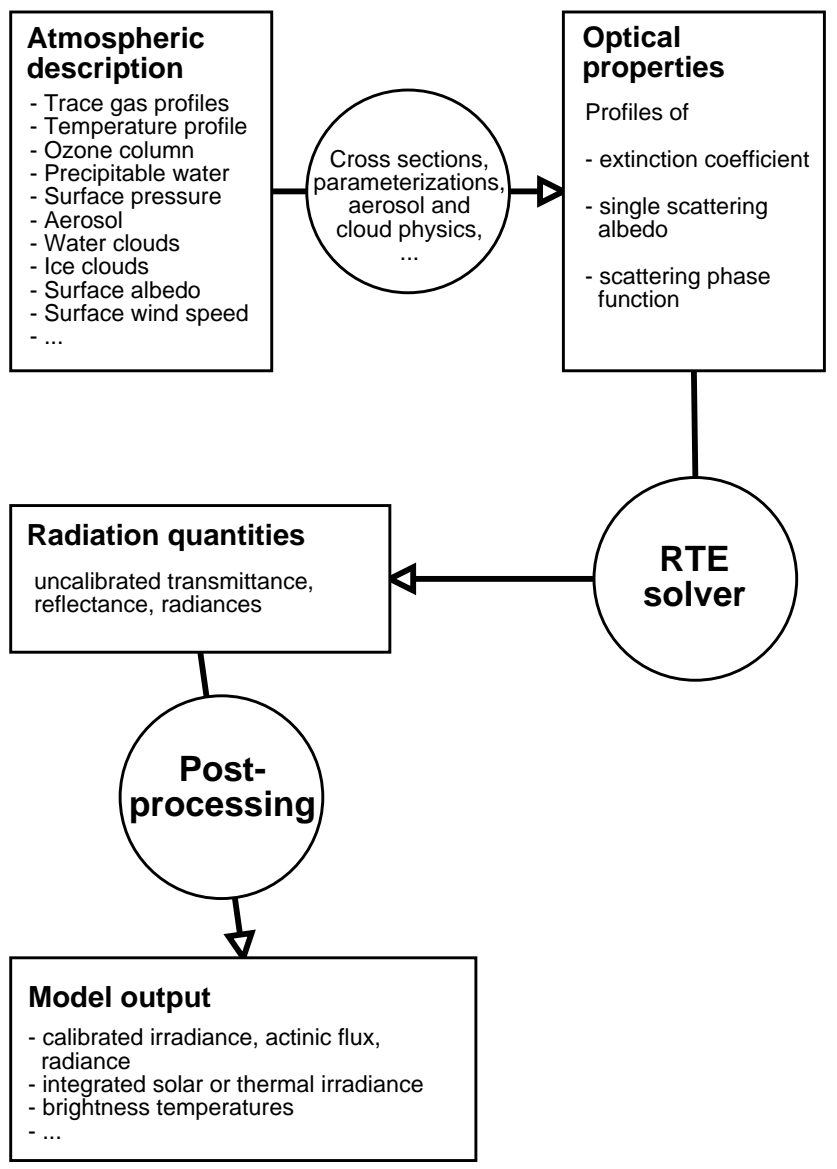

Fig. 1. Structure of the uvspec model.

and dens_column O3 340.0 DU which takes three parameters and scales the ozone column to 340 Dobson units in this example. The format of the output file depends on the choosen radiative transfer equation solver and the output options specified by the user. The output always includes the direct and diffuse downward, and the diffuse upward irradiances. Actinic flux and radiances for arbitrary angles may be requested by the user. A complete description is given in the libRadtran User's Guide.

A unique feature of uvspec is that the user has a choice of various radiative transfer equation solvers which are selected by the rte_solver option in the input file. This way, for the radiative transfer problem at hand an appropriate solver may be chosen, e.g. a fast two-stream code to calculate approximate irradiance or a discrete ordinate code to accurately simulate radiances, with or without polarization. Details about the solvers are given below.

The uvspec model includes the following three essential parts: (1) An atmospheric shell which converts atmospheric properties like ozone profile, surface pressure, or cloud microphysical parameters into optical properties required as input to (2) the radiative transfer equation solver which calculates radiances, irradiances, and actinic fluxes for the given optical properties; finally (3) post-processing of the solver output including multiplication with the extraterrestrial solar irradiance, correction of Earth-Sun distance, convolution with a slit function, or integration over wavelength (depending on the choice of the user). For an overview see Fig. 1. The components are described in the following.

\subsection{Radiative transfer equation solvers}

At the heart of all radiative transfer models is a procedure to calculate the radiation field for a given distribution of optical properties. This procedure ranges from a variety of parameterizations and approximations to sophisticated and accurate solutions of the full three-dimensional radiative transfer equation. The radiative transfer equation may be written as (Chandrasekhar, 1960; Thomas and Stamnes, 1999)

$\frac{d L}{\beta d s}=-L+J$,

where the source function $J$ is defined as

$J=\frac{\omega}{4 \pi} \int p\left(\boldsymbol{\Omega}, \boldsymbol{\Omega}^{\prime}\right) L\left(\boldsymbol{\Omega}^{\prime}\right) d \boldsymbol{\Omega}^{\prime}+(1-\omega) B(T)$.

Here $L$ is the radiance at location $(x, y, z), \beta$ the volume extinction coefficient, $\omega$ the single scattering albedo, $p\left(\boldsymbol{\Omega}, \boldsymbol{\Omega}^{\prime}\right)$ the phase function giving the likelihood of a scattering event redistributing radiation from direction $\boldsymbol{\Omega}^{\prime}$ to $\boldsymbol{\Omega}$, and $B(T)$ the Planck function. The latter can usually be neglected for wavelengths below about $4 \mu \mathrm{m}$. Numerous methods exist to solve Eq. (1). The problem at hand sets conditions that must be satisfied when solving the radiative transfer equation.

As opposed to most other radiative transfer models, uvspec is not based on a single method to solve Eq. (1) but rather includes a number of different radiative transfer equation solvers (Table 1). Thus, given a problem, the user may easily choose the appropriate solver. Once the radiative transfer equation is solved a number of radiative quantities are calculated. These include the downward direct and diffuse $E_{\downarrow}$ irradiances and the upward $E_{\uparrow}$ irradiance:

$$
\begin{aligned}
E_{\downarrow} & =\int_{2 \pi} L(\boldsymbol{\Omega}) \cos \theta d \boldsymbol{\Omega} \\
& =\int_{0}^{2 \pi} \int_{\pi / 2}^{\pi} L(\theta, \phi) \cos \theta \sin \theta d \theta d \phi \\
E_{\uparrow} & =\int_{0}^{2 \pi} \int_{0}^{\pi / 2} L(\theta, \phi) \cos \theta \sin \theta d \theta d \phi
\end{aligned}
$$

and the corresponding actinic fluxes

$$
\begin{aligned}
F_{\downarrow} & =\int_{2 \pi} L(\boldsymbol{\Omega}) d \boldsymbol{\Omega} \\
& =\int_{0}^{2 \pi} \int_{\pi / 2}^{\pi} L(\theta, \phi) \sin \theta d \theta d \phi \\
F_{\uparrow} & =\int_{0}^{2 \pi} \int_{0}^{\pi / 2} L(\theta, \phi) \sin \theta d \theta d \phi .
\end{aligned}
$$


Table 1. The radiative transfer equation solvers currently implemented in uvspec.

\begin{tabular}{|c|c|c|c|c|}
\hline $\begin{array}{l}\text { RTE } \\
\text { solver }\end{array}$ & Geometry & $\begin{array}{l}\text { Radiation } \\
\text { quantities }\end{array}$ & Reference & Comments \\
\hline DISORT 1.3 & 1-D, PP & $\mathrm{E}, \mathrm{F}, \mathrm{L}$ & Stamnes et al. (1988) & discrete ordinate \\
\hline DISORT 2.0 & $1-\mathrm{D}, \mathrm{PP}$ & $\mathrm{E}, \mathrm{F}, \mathrm{L}$ & Stamnes et al. (2000) & discrete ordinate \\
\hline POLRADTRAN & 1-D, PP & $\mathbf{E}, \mathbf{F}, \mathbf{L}$ & Evans and Stephens (1991) & polarization included \\
\hline twostr & 1-D, PS & $\mathrm{E}, \mathrm{F}$ & Kylling et al. (1995) & $\begin{array}{l}\text { two stream; } \\
\text { pseudo-spherical correction for low sun angles; }\end{array}$ \\
\hline sdisort & 1-D, PS & $\mathrm{E}, \mathrm{F}, \mathrm{L}$ & Dahlback and Stamnes (1991) & $\begin{array}{l}\text { pseudo-spherical correction for low sun angles; } \\
\text { double precision, customized for airmass calculations }\end{array}$ \\
\hline spsdisort & 1-D, PS & E, F, L & Dahlback and Stamnes (1991) & $\begin{array}{l}\text { pseudo-spherical correction for low sun angles; } \\
\text { single precision, not suitable for cloudy conditions }\end{array}$ \\
\hline tzs & 1-D, PP & L(TOA) & & thermal, zero scattering \\
\hline sss & 1-D, PP & L(TOA) & & solar, single scattering \\
\hline mystic & 3-D, PP & E, F, L & Mayer $(1999,2000)$ & Monte Carlo $^{(a)}$ \\
\hline \multicolumn{5}{|c|}{ (a) not included in the free package; available in joint projects } \\
\hline Explanation: & $\begin{array}{l}\text { PP, plane-p } \\
\text { PS, pseudo } \\
\text { 1-D, one-d } \\
\text { 3-D, three- }\end{array}$ & $\begin{array}{l}\text { rallel } \\
\text { pherical } \\
\text { nensional } \\
\text { imensional }\end{array}$ & $\begin{array}{l}\text { E, irradiance } \\
\mathrm{F} \text {, actinic flux } \\
\mathrm{L} \text {, radiance } \\
\mathrm{L} \text { (TOA), radiance at top of atm }\end{array}$ & sphere \\
\hline $\mathbf{E}, \mathbf{F}$, & $\mathbf{L}$ indicate & ector quanti & & \\
\hline
\end{tabular}

Here $\theta$ and $\phi$ are the polar and azimuth angles, respectively. Other quantities may also be calculated, see Table 1 and the examples in Sect. 4.

The radiation quantities in Eqs. (1-6) are scalar. The corresponding full vector radiation quantities are calculated if the POLRADTRAN solver is invoked which accounts for polarization. Most of the solvers are plane-parallel (PP), that is, they neglect the Earth's curvature and assume an atmosphere of parallel homogeneous layers. This is generally a good assumption for solar and observation zenith angles smaller than about $70^{\circ}$ (Dahlback and Stamnes, 1991). Some of the solvers include a so-called pseudo-spherical (PS) correction which treats the direct solar beam in spherical geometry and the multiple scattering in plane-parallel approximation (Dahlback and Stamnes, 1991). These usually provide a reasonable solution for low sun. For low observation angles (e.g. for limb scan geometry), however, the pseudo-spherical correction does not improve the result. Here, a fully-spherical solver is required which is currently not provided by uvspec. Also, the three-dimensional MYSTIC (Monte Carlo code for the physically correct tracing of photons in cloudy atmospheres) solver (Mayer, 1999, 2000), mentioned in Table 1, is not included in the libRadtran distribution. Due to the complexity of three-dimensional problems we prefer to solve those in close collaboration and interested groups are therefore invited to contact Bernhard Mayer.

\subsection{Spectral resolution}

The spectral resolution may be treated in four different ways by uvspec. The spectrally resolved calculation and the lineby-line calculation are more or less exact methods. The correlated- $k$ distribution and the pseudo-spectral calculation are approximations that provide a compromise between speed and accuracy. In the following the four methods are described including a discussion of the applicability for a specific purpose.

\subsubsection{Spectrally resolved calculation}

A spectrally resolved calculation is the most straightforward way, and will be the choice for most users interested in the ultraviolet and visible spectral ranges. In the UV and visible gas absorption generally occurs in broad bands with only slow spectral variation, the most important of these being the Hartley, Huggins, and Chappuis bands of ozone. Hence, a radiative transfer calculation with $0.5 \mathrm{~nm}$ steps below $350 \mathrm{~nm}$ and $1 \mathrm{~nm}$ steps above $350 \mathrm{~nm}$ is sufficient for most applications. On the other hand, the solar spectrum is highly variable with wavelength, due to the Fraunhofer lines. The general idea was therefore to calculate the atmospheric transmission with moderate resolution, interpolate to the high resolution of the extraterrestrial irradiance, and multiply both. Figure 2 gives an example of this method.

Absorption cross sections for various species are included in uvspec, see Table 2. However, this method is only applicable in the ultraviolet and parts of the visible spectrum. At longer wavelengths the atmospheric transmittance is highly variable with wavelength, due to the narrow rotation-vibration lines of various species. For spectrally resolved calculations the water vapour and oxygen absorption bands are not included, thus this approach is certainly not applicable above $800 \mathrm{~nm}$. See further discussion in Sect. 2.3.1. Spectrally resolved calculations are the default in uvspec. 

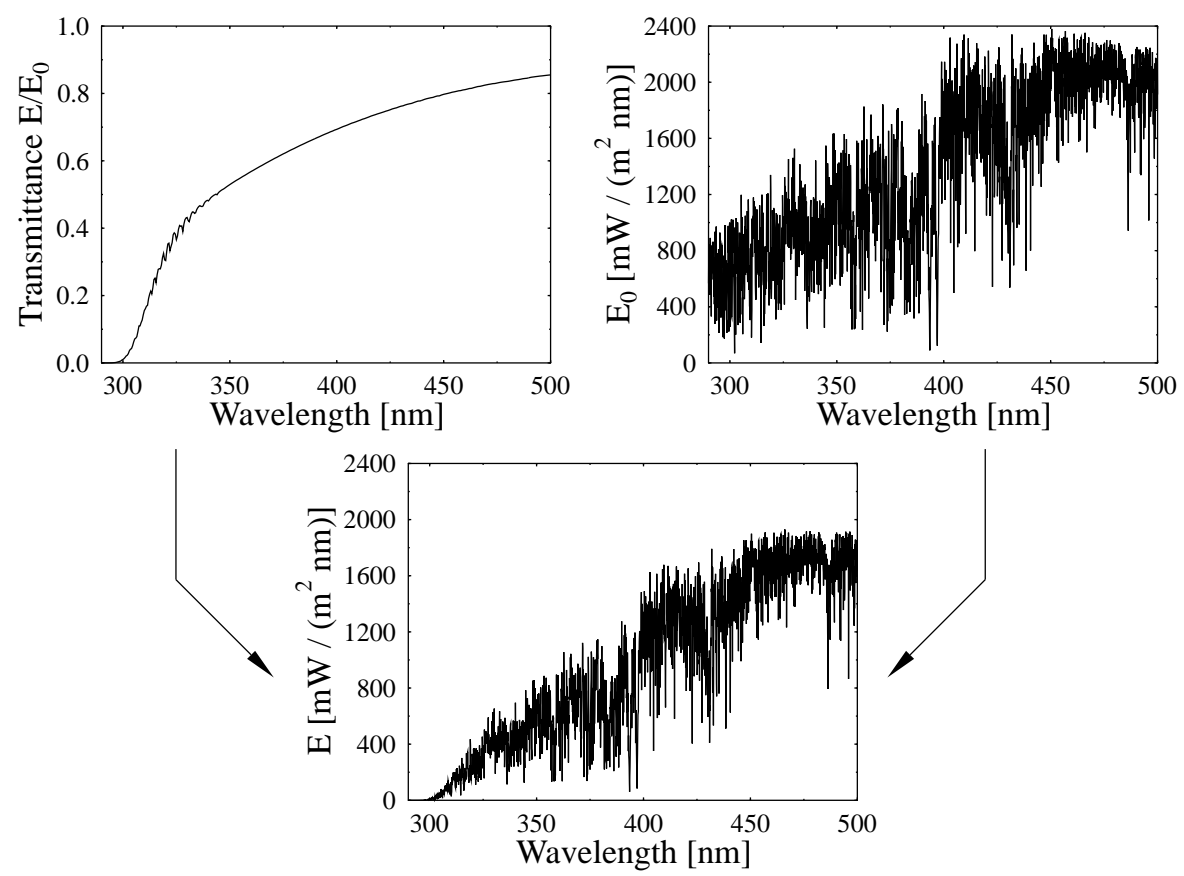

Fig. 2. uvspec calculation of spectral irradiance in the ultraviolet range. (Top left) Low-resolution atmospheric transmittance for US standard atmosphere, solar zenith angle $0^{\circ}$. (Top right) High-resolution extraterrestrial irradiance (Kurucz, 1992), averaged over $0.1 \mathrm{~nm}$ intervals. (Bottom) Product of both: spectral irradiance.

Table 2. The various trace gases and corresponding cross sections included in the libRadtran package. Where more than one cross section is given, the user may choose which one to use by setting the appropriate option.

\begin{tabular}{|c|c|c|c|c|c|}
\hline \multirow[t]{3}{*}{ Trace gas } & \multicolumn{4}{|c|}{ Availability } & \multirow[t]{2}{*}{ Source of absorption cross sections } \\
\hline & spectral & kato & $\mathrm{fu}$ & lowtran & \\
\hline & $250-800 \mathrm{~nm}$ & solar & $\begin{array}{l}\text { solar, } \\
\text { thermal }\end{array}$ & $\begin{array}{l}\text { solar, } \\
\text { thermal }\end{array}$ & \\
\hline $\mathrm{O}_{3}$ & $\checkmark$ & $\checkmark$ & $\checkmark$ & $\checkmark$ & Bass and Paur (1985); Malicet et al. (1995); Molina and Molina (1986) \\
\hline $\mathrm{NO}_{2}$ & $\checkmark$ & & & $\checkmark$ & Burrows et al. (1998) \\
\hline $\mathrm{BrO}$ & $\checkmark$ & & & & Cox et al. (1982); Wahner et al. (1988) \\
\hline $\mathrm{OClO}$ & $\checkmark$ & & & & Wahner et al. (1987) \\
\hline $\mathrm{HCHO}$ & $\checkmark$ & & & & Cantrell et al. (1990) \\
\hline $\mathrm{H}_{2} \mathrm{O}$ & & $\checkmark$ & $\checkmark$ & $\checkmark$ & Hitran; Ricchiazzi et al. (1998); Pierluissi and Peng (1985) \\
\hline $\mathrm{O}_{2}$ & & $\checkmark$ & $\checkmark$ & $\checkmark$ & Hitran; Ricchiazzi et al. (1998); Pierluissi and Peng (1985) \\
\hline $\mathrm{CO}_{2}$ & & $\checkmark$ & $\checkmark$ & $\checkmark$ & Hitran; Ricchiazzi et al. (1998); Pierluissi and Peng (1985) \\
\hline $\mathrm{CH}_{4}$ & & & $\checkmark$ & $\checkmark$ & Hitran; Ricchiazzi et al. (1998); Pierluissi and Peng (1985) \\
\hline $\mathrm{N}_{2} \mathrm{O}$ & & & $\checkmark$ & $\checkmark$ & Hitran; Ricchiazzi et al. (1998); Pierluissi and Peng (1985) \\
\hline $\mathrm{CO}$ & & & & $\checkmark$ & Ricchiazzi et al. (1998); Pierluissi and Peng (1985) \\
\hline $\mathrm{NH}_{3}$ & & & & $\checkmark$ & Ricchiazzi et al. (1998); Pierluissi and Peng (1985) \\
\hline NO & & & & $\checkmark$ & Ricchiazzi et al. (1998); Pierluissi and Peng (1985) \\
\hline $\mathrm{SO}_{2}$ & & & & $\checkmark$ & Ricchiazzi et al. (1998); Pierluissi and Peng (1985) \\
\hline F11 & & & $\checkmark$ & & \\
\hline F12 & & & $\checkmark$ & & \\
\hline $\mathrm{F} 22$ & & & $\checkmark$ & & \\
\hline
\end{tabular}




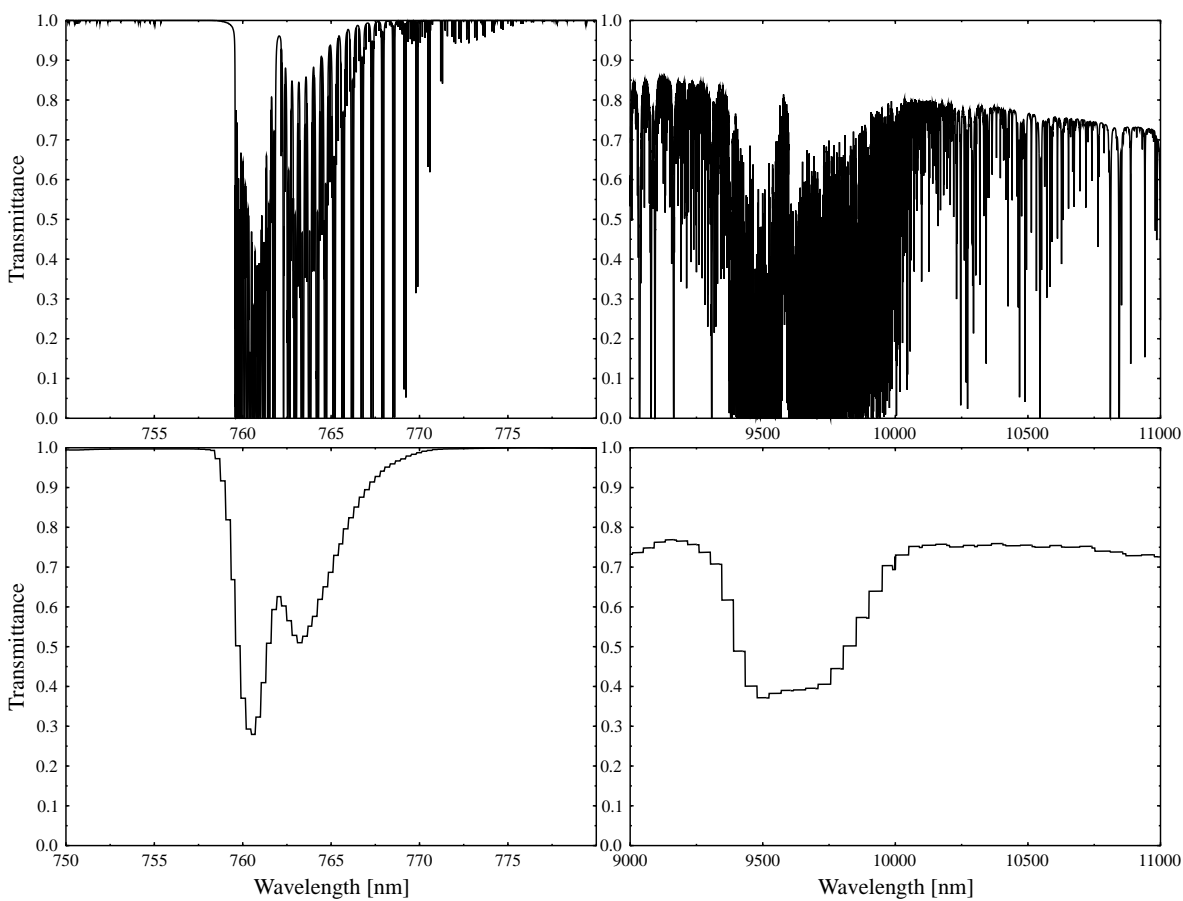

Fig. 3. uvspec direct transmittance in the oxygen A-band around $760 \mathrm{~nm}$ (left) and in the IR window region (right), for the midlatitude summer atmosphere of Anderson et al. (1986). (Top) line-by-line calculation, based on spectral absorption cross sections provided by genln2; (bottom) pseudo-spectral calculation, based on the LOWTRAN absorption parameterization.

\subsubsection{Line-by-line calculation}

In the infrared, molecular absorption spectra are characterized by thousands of narrow absorption lines. There are two ways to treat these, either by highly resolved spectral calculations, so-called line-by-line calculations, or by band parameterizations. Concerning line-by-line, uvspec offers the possibility to define a spectrally resolved absorption cross section profile using molecular_tau file. There is no option in libRadtran to generate such a molecular_tau_file, because (1) the high resolution transmission molecular absorption database (http://www.hitran.com) which forms the basis for such calculations amounts to about 100 MByte which are updated continuously; and (2), there are sophisticated line-by-line programs available, like e.g. genln2 (Edwards, 1992). Using genln 2 it is straightforward to create molecular absorption profiles for uvspec line-by-line calculations. Figure 3 shows an example of a line-by-line calculation of the atmospheric transmittance in two selected solar and thermal spectral ranges, the oxygen A absorption band around $760 \mathrm{~nm}$ and a region within the infrared atmospheric window around $10 \mu \mathrm{m}$.

All spectral lines in the left figure are due to absorption by oxygen, while the ones in the right figure are due to ozone, water vapour, and carbon dioxide. Line-by-line calculations are obviously the most accurate but also the most time-consuming way to make radiation calculations.

\subsubsection{Correlated- $k$ and pseudo-spectral calculations}

For most applications, however, line-by-line calculations are far too slow. Here one needs a band parameterization, and the most accurate of these is the so-called correlated- $k$ approximation (Lacis and Oinas, 1991; Yang et al., 2000). Several correlated- $k$ parameterizations have been implemented in uvspec. These are invoked with the option correlated_k followed by one of the following:

kato. The parameterization by Kato et al. (1999). It covers the solar spectral range with 32 spectral bands and includes 575 subbands in total, that is, 575 calls to the rtesolver. The absorption coefficients are based on HITRAN 1992.

kato2. A new, optimized version of the above tables (Seiji Kato, private communication 2003), with the same 32 spectral bands but only 148 subbands (that is, calls to the rte_solver). The uncertainty is only slightly higher than kato. The absorption coefficients are based on HITRAN 2000 .

fu. The Fu and Liou (1992) is a fast parameterization developed for climate models. It covers both the solar shortwave and the terrestrial longwave. 


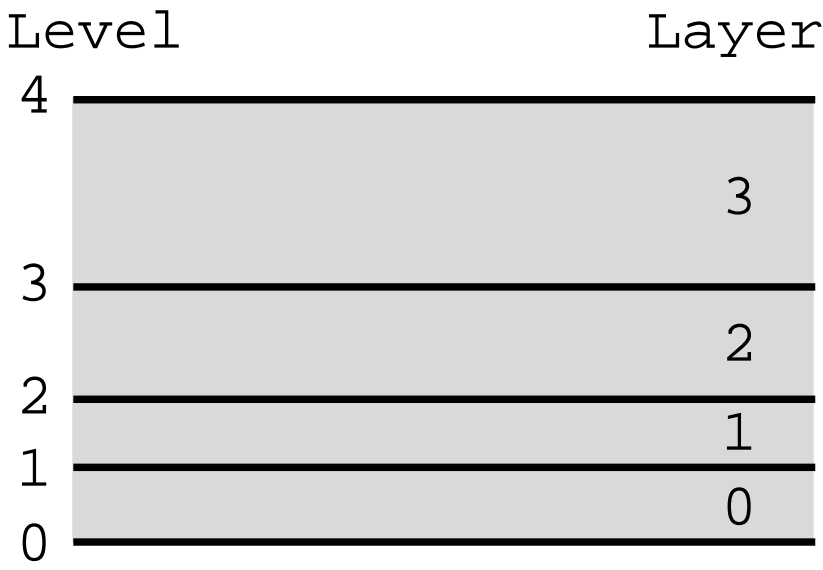

Fig. 4. Model levels versus model layers.

avhrr_kratz. The Kratz and Varanasi (1995) parameterization covers the Advanced Very High Resolution Radiometer (AVHRR) instrument channels which are calculated as a linear combination of the bands output by uvspec.

lowtran. The lowtran option is actually not a real correlated- $k$ parameterization, but allows pseudo-spectral calculations covering the whole spectral range. It has been adopted from the SBDART radiative transfer model (Ricchiazzi et al., 1998) from which we quote

SBDART relies on low-resolution band models developed for the LOWTRAN 7 atmospheric transmission code (Pierluissi and Peng, 1985). These models provide clear-sky atmospheric transmission from 0 to $50000 \mathrm{~cm}^{-1}$ and include the effects of all radiatively active molecular species found in the Earth's atmosphere. The models are derived from detailed line-by-line calculations that are degraded to $20 \mathrm{~cm}^{-1}$ resolution for use in LOWTRAN. This translates to a wavelength resolution of about $5 \mathrm{~nm}$ in the visible and about $200 \mathrm{~nm}$ in the thermal infrared. These band models represent rather large wavelength bands, and the transmission functions do not necessarily follow Beers Law. This means that the fractional transmission through a slab of material depends not only on the slab thickness, but also on the amount of material penetrated before entering the slab. Since the radiative transfer equation solved by SBDART assumes Beers Law behavior, it is necessary to express the transmission as the sum of several exponential functions (Wiscombe and Evans, 1977). SBDART uses a three-term exponential fit, which was also obtained from LOWTRAN 7. Each term in the exponential fit implies a separate solution of the radiation transfer equation. Hence, the RT equation solver only needs to be invoked three times for each spectral increment. This is a great computational economy compared to a higher order fitting polynomial, but it may also be a source of significant error.

user_specified. Allows a user-defined correlated- $k$ parameterization for a specific atmospheric profile.

For more information on these parameterizations please refer to the libRadtran documentation and the referenced publications. Correlated- $k$ is a powerful way to calculate spectrally integrated quantities, however, it takes away some flexibility. In particular this implies that the wavelength grid is no longer chosen by the user but by the parameterization. The uvspec output is then no longer spectral quantities, e.g. $\mathrm{W} /\left(\mathrm{m}^{2} \mathrm{~nm}\right)$, but integrated over the spectral bands, e.g. $\mathrm{W} / \mathrm{m}^{2}$. Note, however that this does not apply for the lowtran option which is still spectral.

\subsection{Atmosphere}

The uvspec model includes five classes of atmospheric constituents: Rayleigh scattering by air molecules, molecular absorption, aerosol, water and ice clouds. Each of those may be defined individually, using a variety of configuration options. The vertical resolution may be different for all components. Internally uvspec will merge the different vertical resolutions onto a common grid to be used by the radiative transfer equation solver, thus giving the user total freedom when specifying the vertical profiles of the various atmospheric constituents. Gaseous, aerosol, and ice cloud optical properties are considered one-dimensional and vary in the vertical only. For water clouds, a full three-dimensional input field may be specified to be used by either the MYSTIC solver or the independent pixel approximation (IPA) (see Sect. 2.3.3). For each of the five classes, either microphysical or optical properties may be defined by the user. E.g. molecular scattering is either defined by profiles of pressure and temperature or by explicitely specifying a profile of optical thickness; ice clouds may either be defined by their ice water content and particle properties (shape and size) or by explicitely defining profiles of extinction coefficient, single scattering albedo, and scattering phase function. Instead of defining complete profiles there is always the possibility to use standard profiles and scale them with a columnar property, e.g. precipitable water, ozone column, or integrated aerosol optical thickness. This gives the user the flexibility to provide the model with whatever information is available and use standard assumptions for the unknown properties.

Please note that there are basically two ways of defining atmospheric properties as model input: at a given level, or for a given layer, see Fig. 4. A model level is simply an altitude. Profiles of pressure, temperature, etc. are usually defined at levels, as they are provided e.g. by radiosondes. A model layer, on the other hand, is an atmospheric layer 
defined by its bottom and top altitude. Some radiative transfer solvers like disort use the concept of layers, assuming that the optical properties of the medium are constant within each layer. Some codes, like e.g. SHDOM by Evans (1998) use the level concept and assume that the optical properties vary linearly between levels. All RTE solvers within libRadtran use the layer concept. This has important implications for the interpretation of the input data: Profiles of pressure, temperature, trace gas concentrations etc. are interpreted as level properties, and interpolated linearly or logarithmically to obtain mean layer properties. Water and ice clouds may be either defined per level (default) or per layer. The layer concept is more meaningful in this case because clouds usually have sharp boundaries. If optical properties, like optical thickness, single scattering albedo, or the scattering phase function are defined as input, these usually refer to model layers, rather than levels. For most input parameters the assignment to level or layer is straightforward. In ambiguous cases, the manual and the verbose option will help to make correct decisions. An arbitrary number of levels may be defined by the user. The standard profiles provided with libRadtran comprise 50 levels between 0 and $120 \mathrm{~km}$ which is a reasonable choice for most applications.

\subsubsection{The molecular atmosphere}

Profiles of pressure, temperature, and concentrations of ozone and optionally oxygen, water vapour, $\mathrm{CO}_{2}$, and $\mathrm{NO}_{2}$, defined in the atmosphere_file form the starting point for any uvspec calculation. These profiles may be specified in a number of ways, the simplest one being to use one of the included atmosphere files by Anderson et al. (1986). For the various trace gases, vertical profiles may be specified in separate input files for each species. Furthermore the vertical column of each species may be scaled. To calculate the optical thickness from the concentration, absorption cross sections are needed. The trace gases currently considered by uvspec are listed in Table 2 including available choices for their cross sections. As has been described in Sect. 2.2, the definition of explicit spectral cross sections is only meaningful in the ultraviolet/visible where the absorption lines are broad enough to be covered explicitely with reasonable wavelength resolution. In the near and far infrared regions, spectral lines are too dense so that an explicit (line-by-line) calculation is not feasible for most practical purposes.

Figure 5 shows the atmospheric transmission in the ultraviolet/visible part of the spectrum and illustrates the contributions of individual components. The spectral calculation includes only ozone and $\mathrm{NO}_{2}$. It is clear that for wavelengths smaller than about $550 \mathrm{~nm}$ the spectral calculation is the method of choice, taking into account that this is by far the fastest method: only a single call to the radiative transfer solver is required per wavelength while for the correlated_k options usually more than one call is required; in the case of correlated_k lowtran three calls to the radiative trans-
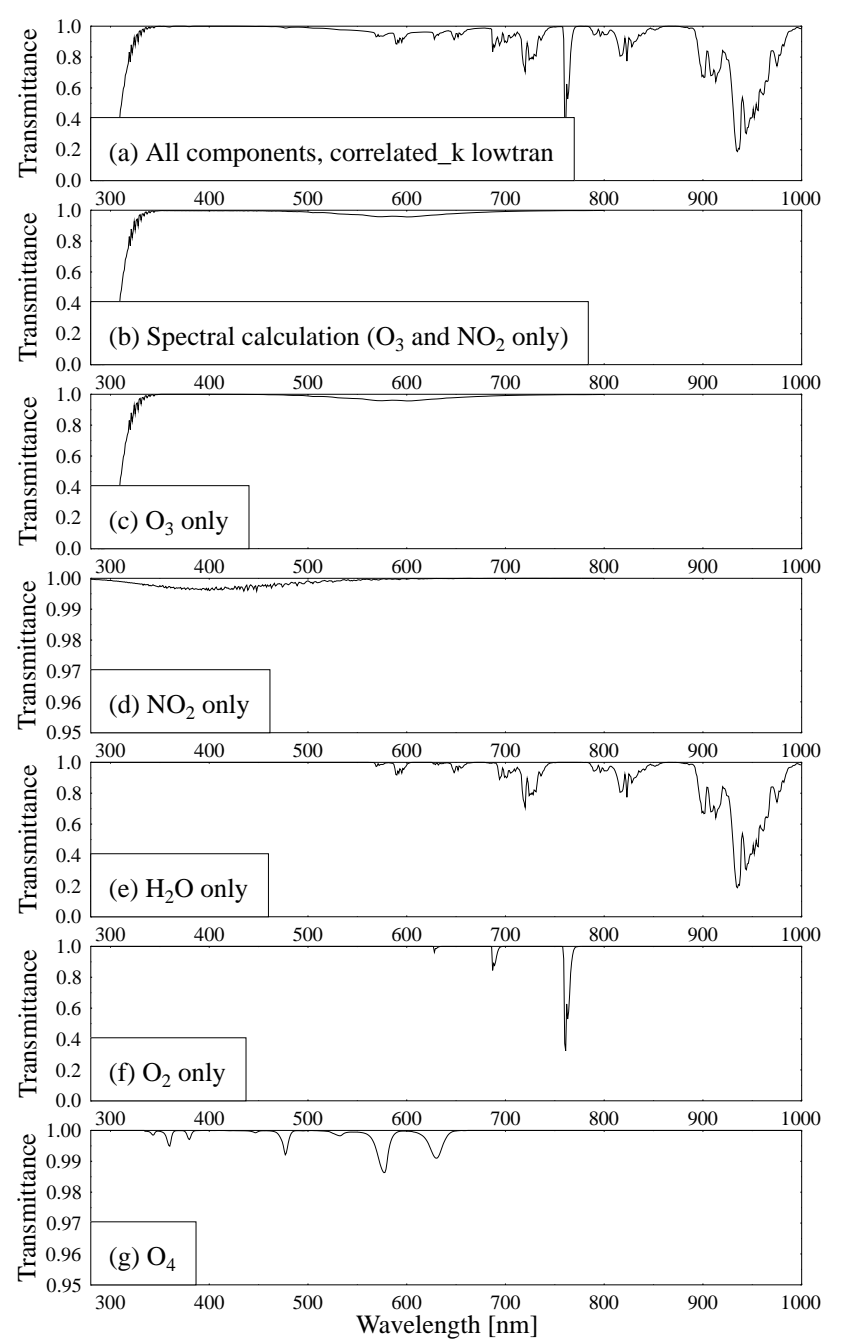

Fig. 5. Spectral direct transmittance of the atmosphere; (a) uvspec calculation with correlated_k lowtran, including all atmospheric components; (b) uvspec spectral calculation, includes only ozone and $\mathrm{NO}_{2} ;(\mathbf{c}-\mathbf{g})$ correlated $\mathbf{k}$ lowtran transmittance, if only one component is considered, see figure keys. Please note the different scales on $y$-axes in figures (d) and (g).

fer solver are required which leads to an about three-fold increase in computational time. Above $550 \mathrm{~nm}$ the uncertainty of the spectral calculation increases, due to the water vapour and oxygen absorption bands, and in the IR the spectral calculation obviously does not make any sense because there strong spectral absorption bands dominate the signal. For completeness, absorption by the $\mathrm{O}_{4}$ complex is included in the figure, as parameterized in LOWTRAN/SBDART, see e.g. Pfeilsticker et al. (1997).

Molecular (Rayleigh) scattering is calculated from the density profile according to Bodhaine et al. (1999). It can be modified e.g. by pressure 1013 which would set the surface pressure to $1013 \mathrm{mbar}$ and scale the profile accordingly. 

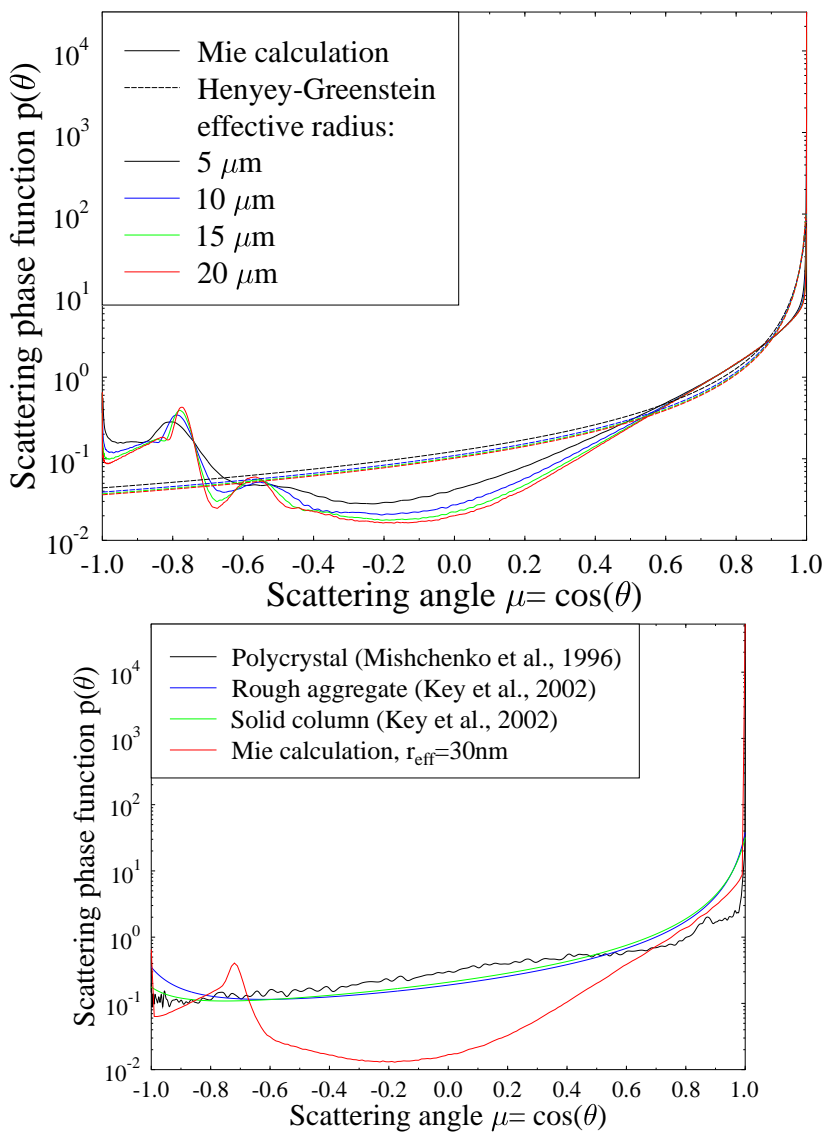

Fig. 6. (Top) Mie scattering phase functions for water clouds with effective radii 5, 10, 15, and $20 \mu \mathrm{m}$ (solid lines). Also shown are the respective Henyey-Greenstein approximations for the four cases, as provided by the parameterization of $\mathrm{Hu}$ and Stamnes (1993) (dashed lines). (Bottom) Ice cloud scattering phase functions for effective radius of $30 \mu \mathrm{m}$ using different parameterizations; (Black) Polycrystal scattering phase function, as used for the ISCCP ice cloud retrieval (Mishchenko et al., 1996); (blue) parameterization by Key et al. (2002) for rough aggregates; (green) same but for solid columns; (red) Mie calculations for spherical ice particles; the figure shows the typical behaviour of non-spherical particles, in particular the large difference in the sideward scattering direction compared to spherical particles.

\subsubsection{Aerosols}

Aerosols are tiny particles suspended in the air. They may originate from a variety of sources including volcanoes, dust storms, forest and grassland fires, living vegetation, and sea spray as well as human activities such as the burning of fossil fuels and the alteration of natural surface cover. In consequence, aerosol properties are highly variable with location and time. Aerosol particles affect the radiation field by absorption and scattering, depending on their origin. The high variability is reflected in the way aerosol is input to uvspec: Aerosols are specified in a hierarchical way. The most simple way to include aerosols is by the option aerosol_default which will include one of the aerosol models by Shettle (1989) with the following properties: rural type aerosol in the boundary layer, background aerosol above $2 \mathrm{~km}$, spring-summer conditions and a visibility of $50 \mathrm{~km}$. These settings may be modified with the options aerosol_haze, aerosol_vulcan, aerosol_season, and aerosol_visibility. More information can be introduced step by step, overwriting the default parameters. For example, aerosol_tau_file, aerosol_ssa_file and aerosol_gg_file, can be used to define profiles of optical thickness, single scattering albedo, and asymmetry parameter. The integrated optical thickness can be set to a constant value using aerosol_set_tau or scaled with aerosol_scale_tau. The single scattering albedo may be scaled by aerosol_scale_ssa or set to a constant value by aerosol_set_ssa. The aerosol asymmetry factor may be set by aerosol_set_gg. The wavelength dependence of the aerosol optical thickness may be specified using the aerosol_angstrom option. For full specification of the aerosol scattering phase function the aerosol_moments_file option is available. If microphysical properties are available these may be introduced by defining the complex index of refraction aerosol_refrac_index or aerosol_refrac file and the size distribution aerosol_sizedist_file. Finally, one may define the aerosol optical properties of each layer explicitely using aerosol_files. This allows the user to calculate aerosol optical properties with any single-scattering program and subsequently input these to uvspec. Full documentation of all aerosol options are included in the libRadtran documentation and some are used in the examples below. This example demonstrates the general philosophy behind libRadtran: the starting point is always a standard model for a component which can be re-defined step-by-step by the user as data are available.

\subsubsection{Clouds}

Both water and ice clouds models are included in uvspec. The easiest way to include a water or ice cloud is to specify vertical profiles of liquid or ice water content and effective droplet/particle radius. These properties may be defined either at model levels or per model layers. The microphysical properties of water clouds are converted to optical properties either according to the Hu and Stamnes (1993) parameterization or by Mie calculations. The latter are very time-consuming, hence they are not included as online calculations within uvspec. Rather there is an option to read in pre-calculated Mie tables which are available at http://www.libradtran.org. These tables are provided for a set of 138 and 219 wavelengths between $250 \mathrm{~nm}$ and $100 \mu \mathrm{m}$ for water and ice, respectively. The wavelengths were chosen such that the linear interpolation of the extinction coefficient, single scattering albedo, and asymmetry parameter never deviate by more than $1 \%$ from the true value. For an overview of typical scattering phase functions for water clouds see Fig. 6 (top). 
The main difference between water and ice clouds is that the latter usually consist of non-spherical particles. Mie calculations for ice particles are only a first guess and certainly not a good approximation. Hence, the conversion from microphysical to optical properties is less well-defined, and several parameterizations are available. The parameterizations by $\mathrm{Fu}$ (1996) and Fu et al. (1998) are suitable for calculation of irradiances. For radiances the parameterization of Key et al. (2002) is available. Which parameterization to use is set by the option ic_properties. For the Key et al. (2002) parameterizations the user may choose between six crystal habits. For an overview of typical scattering phase functions for ice clouds see Fig. 6 (bottom). The figure clearly shows that the parameterization by Key et al. (2002) approximates the calculated phase function reasonably well. It is also clear from the figure that ice particles should not be treated with Mie theory due to the large systematic difference particularly in the sideward direction.

As for the aerosol, there are several options to modify the optical properties of water and ice clouds. And of course there is also the option of defining all water and ice cloud properties explicitely using the options wc_files and ic_files.

Clouds are complex three-dimensional distributions of water and ice particles. Full three-dimensional solvers like MYSTIC may handle realistic inhomogeneous clouds - usually for a high prize, consisting not only in a considerably higher computational cost, but even more important, the need to feed the model with realistic cloud structures. For many applications, simpler approximations usually provide a reasonable alternative. The simplest clouds handled by radiative transfer equation solvers consist of homogeneous layers which, however, is not necessarily a good assumption in general, see e.g. Cahalan et al. (1994a,b); Scheirer and Macke (2003). One approach to approximate horizontally inhomogeneous clouds with one-dimensional solvers is the independent pixel approximation (IPA) (Cahalan et al., 1994b). The IPA ignores horizontal photon transport but includes horizontal inhomogeneities in the cloud optical properties. Even if nothing about the cloud structure is known, a simple approximation like handling only the cloudy part and the cloudless part of a scene with the independent pixel method (using only the cloud fraction as an extra parameter) is already a large improvement. For many applications, clouds are and need to be treated plane-parallel, e.g. for remote sensing applications. Plane-parallel clouds are the default with uvspec. IPA calculations may also readily be performed using the ic ipa_files and wc ipa files options. An example for an IPA calculation is given in this paper.

\subsection{Surface}

All the radiative transfer equation solvers in Table 1 may include a Lambertian reflecting lower surface. The albedo of this surface may be set to a constant value for all wavelengths by the albedo option or given wavelength dependent

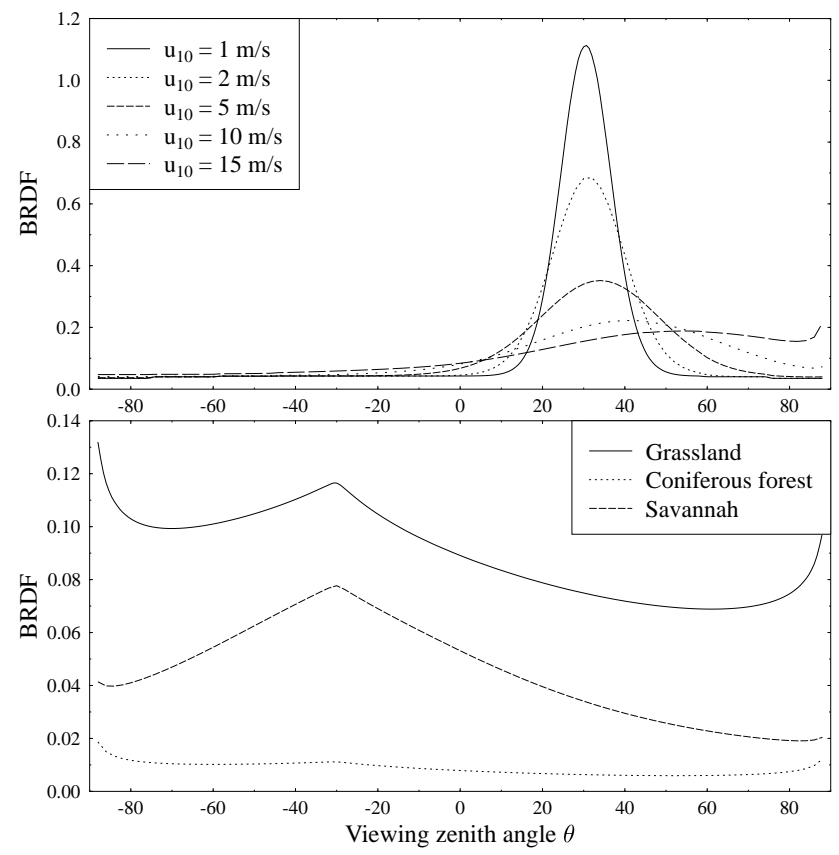

Fig. 7. (Top) BRDF of a water surface for different wind speeds at $400 \mathrm{~nm}$; the figure shows the solar principle plane; the sun is at $-30^{\circ}$; a positive viewing angle means that the sensor looks into the direction of the sun; (bottom) BRDF of different land surfaces in the visible spectral range; as expected, the specular reflection of the water surface occurs opposite the direction of incidence while the vegetation hot spot appears in the backscatter direction.

behaviour by the option albedoffile. For the DISORT 2.0 and the MYSTIC solvers bidirectional reflectance distribution functions (BRDF) for a variety of surfaces may be specified based on the parameterization of Rahman et al. (1993). A parameterization of the BRDF of water surfaces is also included which depends mainly on wind speed and to a lower degree on plankton concentration and salinity. In contrast to the vegetation where the typical hot spot occurs in the $180^{\circ}$ backscatter direction, here the main feature is specular reflection. The parameterization in uvspec was adopted from the $6 \mathrm{~S}$ code (Vermote et al., 1997) and is based on the measurements of Cox and Munk (1954a,b) and the calculations of Nakajima and Tanaka (1983). Figure 7 shows examples of the BRDF of land and water surfaces, as parameterized in uvspec.

\subsection{Solar flux}

Several different extraterrestrial spectra are available with variable resolution and accuracy. The extraterrestrial spectra included in libRadtran are listed in Table 3.

For convenience also some combined spectra are provided e.g. atlas_plus_modtran which is a combination of Atlas $3(200-407.8 \mathrm{~nm})$, Atlas $2(407.8-419.9 \mathrm{~nm})$, and Modtran $3.5(419.9-800 \mathrm{~nm})$. For some wavelength resolutions, 
Table 3. The various extraterrestrial (ET) spectra included in the libRadtran package.

\begin{tabular}{llll}
\hline $\begin{array}{l}\text { ET } \\
\text { spectrum }\end{array}$ & $\begin{array}{l}\text { Wavelength } \\
\text { range }(\mathrm{nm})\end{array}$ & $\begin{array}{l}\text { Resolution } \\
(\mathrm{nm})\end{array}$ & Reference \\
\hline Atlas 2 & $200-420$ & 0.05 & Woods et al. (1996) \\
Atlas 3 & $200-407$ & 0.05 & Woods et al. (1996) \\
Kurucz & $250-10000$ & $0.1 / 1.0$ & Kurucz (1992) \\
Gueymard & $0.5-10^{6}$ & variable & Gueymard (2003) \\
\hline
\end{tabular}

for example the correlated- $k$ options, see Sect. 2.2, special extraterrestrial spectra are provided where the extraterrestrial flux has been integrated over the bands used by the particular correlated- $k$ parameterization. The extraterrestrial spectrum may be freely specified by the user. A special transmittance option to uvspec sets the extraterrestrial spectrum to one for all wavelengths allowing the transmittance and the reflectivity to be readily calculated. Finally, if the user specifies the day_of_year the extraterrestrial spectrum is adjusted for the Earth-Sun distance.

\subsection{Post processing}

The main output of uvspec is a spectrum. However, this spectrum may be manipulated in several ways. This includes convolution of the spectrum with a slit function and interpolation to selected output wavelengths using the slit_function_file and spline or spline file options; multiplication of the spectrum with a filter function using filter_function file and in addition specifying output sum or output integrate to sum or integrate the (filter-weighted) spectra. Whether to sum or integrate depends on the extraterrestrial solar flux. Normally one would integrate if doing a spectral or line-by-line calculation and sum if doing a correlated- $k$ calculation (except for correlated_k lowtran).

\subsection{Output}

The output from uvspec consists of one block per wavelength. The contents of each block depends on what output the user has requested. In the simplest and default case the block is a single line giving the wavelength and direct and diffuse irradiances and actinic fluxes for the bottom of the atmosphere. Using the zout option the user may specify one or more output altitudes. The wavelength range is specified by the wavelength option, but see also the spline, spline file and output options. Additional output lines are added if radiances are requested at angles specified by the umu and phi options. The output also depends on the radiative solver used as some solvers provide more information than others, e.g. the polradtran solver includes polarization. Finally the radiation quantities may be output as transmittances, reflectivities and brightness temperatures using the transmittance, reflec- tivity, and brightness options, respectively. All details of the uvspec output are described in the LibRadtran User's Guide that comes with the software package.

\subsection{Specials}

Several special options are available to handle various tasks. These include the include option for including a file in the uvspec input file; various no_options for turning off absorption (no_absorption), molecular absorption (no_molecular_absorption), scattering (no_scattering) and Rayleigh scattering (no_rayleigh); an option quiet for turning off informative messages and vice versa the option verbose to get detailed and numerous information. The verbose option is highly recommended whenever an input file for a new problem is generated because it helps to verify that the model actually does what one wants it to do. The option reverse may be used to turn the atmosphere upside down which may sometimes be convenient.

\subsection{Model validation}

Models must be checked against measurements and other models to ensure their correct behaviour. Also, continuous checking of models during development is important to avoid introduction of errors. This includes both testing of individual parts of the model and the complete model. For example, the various DISORT solvers (Stamnes et al., 1988, and Table 1), the twostr solver (Kylling et al., 1995), and the POLRADTRAN solver (Evans and Stephens, 1991) have been carefully tested against analytical as well as earlier model results by their developers. Over the years the tools within the libRadtran package have been thoroughly tested and compared against measurements and other models. Furthermore, the package contains numerous automated tests that the users may run to check their installation. These tests are also frequently used to ensure that all existing features are still working as expected when introducing new additions to the package.

The most comprehensive tool within the libRadtran package is the uvspec radiative transfer model. The very first uvspec model versus measurement comparison involved stratospheric balloon measurements of direct and scattered solar radiation in the UV (Kylling et al., 1993). Since then the uvspec model has been compared against surface spectral UV irradiance measurements (Mayer et al., 1997; Kylling et al., 1998; Van Weele et al., 2000); surface spectral UV actinic flux measurements (Bais et al., 2003); airborne spectral UV actinic flux data (Hofzumahaus et al., 2002); surface integrated UV irradiance (DeBacker et al., 2001); surface photolysis frequency measurements (Hofzumahaus et al., 2004; Shetter et al., 2003); stratospheric balloon measurements of the actinic flux at large solar zenith angles (Kylling et al., 2003a); airborne visible spectral irradiance measurements (Wendisch and Mayer, 2003); and both surface and airborne 
measurements of the spectral UV irradiance and actinic flux (Kylling et al., 2005).

While measurements may appear to be the ultimate test for a model, the measurements themselves pose a potential problem. Measurements are associated with uncertainties and they may be affected by changing environmental conditions. A complete model versus measurement comparison requires a closure experiment where all input to the model is measured as well as the output. Complete input information is rarely available even for cloudless sky since, for example, vertical measurements of the single scattering albedo and phase function of aerosols are not presently achievable. Thus, all model versus measurements comparisons need some assumptions about the model input. These assumptions and their influence on the results must be kept in mind while validating models against measurements. Taking into account the measurement uncertainties and the model uncertainties reported in the above cited papers, the uvspec model is found to agree with the measurement in the troposphere and stratosphere in the UV and visible part of the solar spectrum.

Some of the above measurement versus model comparison papers also include model versus model comparisons (Van Weele et al., 2000; Bais et al., 2003; Hofzumahaus et al., 2004; Shetter et al., 2003). In addition to these the uvspec model has also successfully participated in a model comparison of UV-indices (Koepke et al., 1998) and the Intercomparison of 3-D Radiation Codes (Cahalan et al., 2005).

As is evident from the above cited papers the uvspec model has been thoroughly validated and checked against both measurements and other models. Thus the user may trust the results produced by the model. However, radiative transfer modelling is a complex topic. Care is thus required from the user to make sure that both the question being asked and the model requirements are properly understood before engaging the model. We also repeat the recommendation to make heavy use of the verbose option.

\section{Other tools}

A number of separate additional tools are included in the libRadtran package. They are listed in Table 4. The tools are written in either $\mathrm{C}$ or Perl depending on which computer language is most appropriate for the problem to be solved. These additional tools are used to 1) calculate input parameters to uvspec (for example zenith, make_slitfunction, mie); 2) manipulate uvspec output (for example angres, Calc_j.pl), and 3) perform repeated calls of uvspec for various applications (for example Gen_o3_tab.pl, Gen_wc_tab.pl, airmass.pl). Finally the Perl module UVTools.pm includes a number of perl functions for preparing uvspec input and processing uvspec output. Description of the various tools are available either in the libRadtran User's Guide or by invok- ing help options when using the tool. Examples of use of some of the tools are provided below.

\section{Examples}

The tools that come with libRadtran may be used for a variety of applications. Here we provide realistic examples of some possible usages. For each example a detailed description of how the various tools were used and sample input files are provided with the libRadtran package. The tools used in each example is listed within parentheses in the example heading.

\subsection{The minimum uvspec input file (uvspec)}

One of the design aims with uvspec was to allow simple problems to be solved simply and at the same time allow for full flexibility and detail in specification of inputs for the advanced user. An example of the simplest possible uvspec input file is provided below.

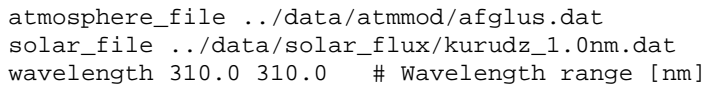

The first line describes the location of the file containing the vertical profiles of pressure, temperature and optional trace gases. It thus defines the vertical resolution of the atmosphere. The second line identifies the location of the extraterrestrial solar flux file which defines the spectral resolution. The third line specifies the wavelength range, here a single wavelength, for which the calculation will be performed. When input to uvspec the above will produce a single line of output including the wavelength, direct, diffuse down- and upward irradiances and actinic fluxes. These radiation quantities will by default be output at the bottom of the atmosphere. Comments are introduced to the input file by a \#. Everything behind the \# on the line is ignored. Obviously other input values are needed to solve the radiative transfer problem for the above atmosphere. These include the solar zenith angle, surface albedo etc. However, uvspec sets default values for these and other variables. The user may start with this simple input file and modify and extend it to encompass the needs to handle the problem at hand.

\subsection{Single spectrum (uvspec)}

The purpose of the very first version of uvspec was to calculate irradiance spectra in the UV and visible part of the spectrum. It is thus appropriate that the first realistic example describes how to use the present uvspec for this purpose. To make the exercise realistic, the measured global (direct plus diffuse) irradiance spectrum in Fig. 8 will be simulated. The spectrum was measured by a Bentham DTM300 double monochromator spectroradiometer during the Actinic flux determination from measurements of irradiance (ADMIRA) campaign in August 2000 at Nea Michaniona, Greece. The atmospheric conditions during the campaign and instrument 
Table 4. Various tools included in the libRadtran package.

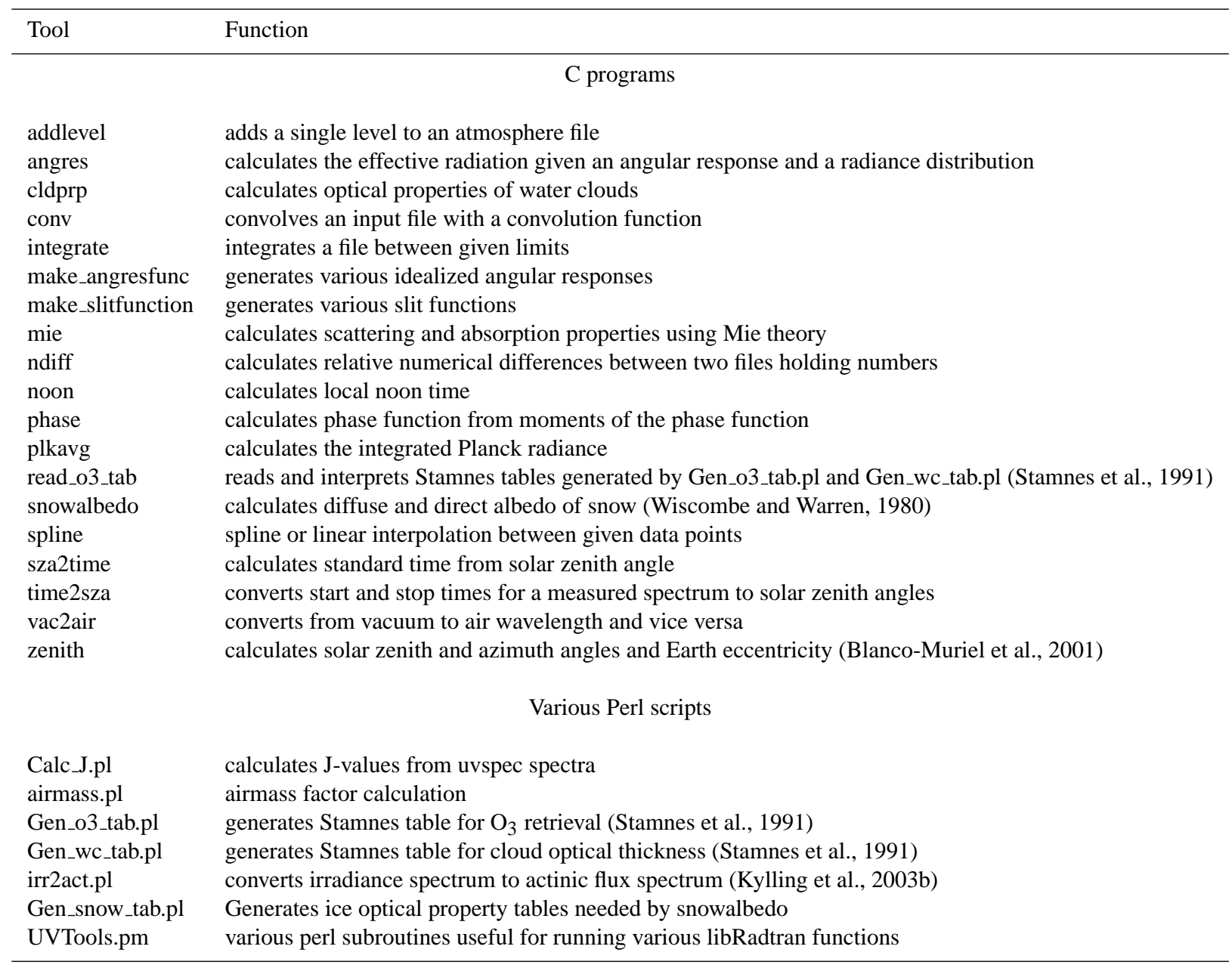

description are provided by Webb et al. (2002). The following input file was generated to simulate the observed spectra as closely as possible, making use of all available ancillary data:

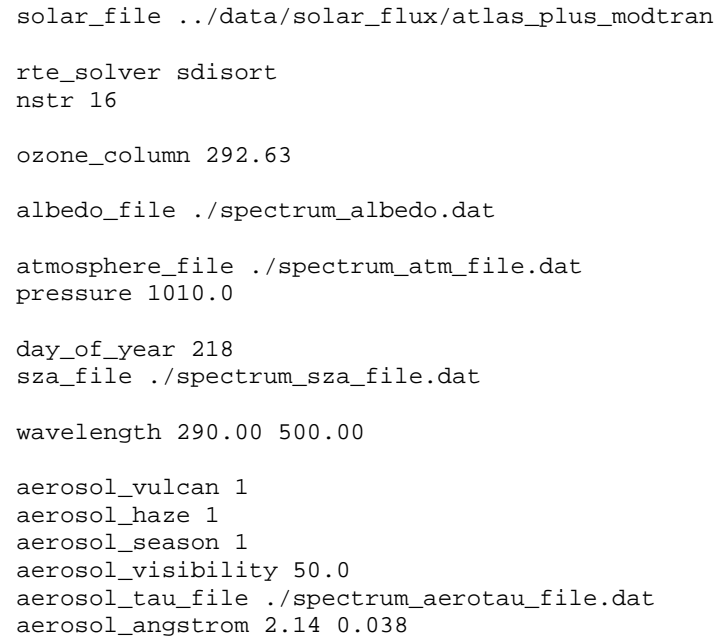

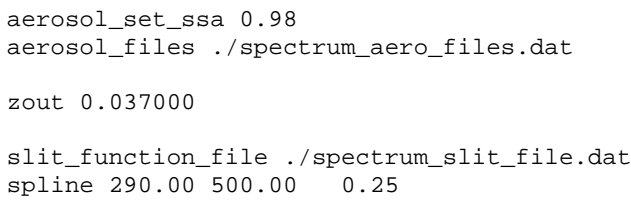

The aerosol optical thickness and the ozone column were derived from direct sun measurements using the technique described by Huber et al. (1995). The aerosol_angstrom 2.14 0.038 option was used to set the Ångström $\alpha(=2.14)$ and $\beta$ (=0.038) parameters. This describes the wavelength dependence of the aerosol optical thickness $\tau_{a}$ by the Angström formula $\tau_{a}(\lambda)=\beta \lambda^{-\alpha}$. The aerosol single scattering albedo was set by the aerosol_set_ssa 0.98 option. This option overrides the values defined by the aerosol_default option. If needed the user may specify the aerosol extinction, single scattering albedo and phase function profiles in all detail by the aerosol_files option. Here this option was used to set the aerosol phase function as derived from a CIMEL sunphotometer. 
The surface albedo was set using the albedo_file option which allows the albedo to be specified as a function of wavelength. Here it increased linearly from 0.01 at $290 \mathrm{~nm}$ to 0.05 at $350 \mathrm{~nm}$ and to 0.08 at $500 \mathrm{~nm}$. The instrument needs some time to scan the spectrum. During this time the solar zenith angle changed from $23.325^{\circ}$ to $25.754^{\circ}$. The sza file option was used to specify the solar zenith angle for each wavelength point. The ozone, pressure, and temperature profiles were given in a separate file identified with atmosphere_file. The ozone column was scaled to 292.63 Dobson units (DU) using the dens_column $\mathbf{O 3}$ 292.63 DU option. The rte_solver sdisort was used to select the double precision pseudospherical disort solver (Table 1), while nstr 16 specified that sdisort was to run in 16 stream mode. The extraterrestrial spectrum was specified by the solar file option. Before the simulated spectrum may be compared with the measured spectrum, the instrument characteristics must be accounted for. This includes convolving the simulated spectrum with the instrument slit function and interpolating the resulting simulated spectrum to the wavelength resolution of the measured spectrum. The slit function may either be an idealized slit function generated by the make_slitfunction tool, or preferably the measured slit function of the instrument. The latter was used here. In either case the slit_function_file and spline options perform the wanted actions.

The resulting simulated spectrum is shown in green in Fig. 8. The ratio of the modelled spectrum over the measured spectrum is shown in blue. Similar cloudless comparisions between measurement and model results have been presented by for example Forster et al. (1995); Mayer et al. (1997); Kylling et al. (1998); Van Weele et al. (2000) and Meloni et al. (2003). The agreement between model simulation and measurement found here is comparable to that reported by those authors. Spectral measurements in the UV are demanding. An error budget for UV measurements has been described by Bernhard and Seckmeyer (1999). For their instrument they estimate $2 \sigma$ equivalent uncertainties between $6.3 \%$ in the UVA to $12.7 \%$ at $300 \mathrm{~nm}$ for a solar zenith angle of $60^{\circ}$. Model simulations also have their uncertainties which have been quantified by Schwander et al. (1997) and Weihs and Webb (1997). The uncertainties associated with the simulations are of a similar magnitude to those of the measurements. Thus it may be concluded that the measurement and model simulation presented in Fig. 8 agree within their uncertainties.

4.3 Optical properties of ice clouds and integrated solar radiation (uvspec)

Cirrus clouds are important for the Earth's climate and their influence on climate depends on their microphysical properties (Stephens et al., 1990). Vice versa, radiation is important for cirrus cloud evolution by radiative cooling and heating, both of which depend on the ice habit (Gu and Liou,

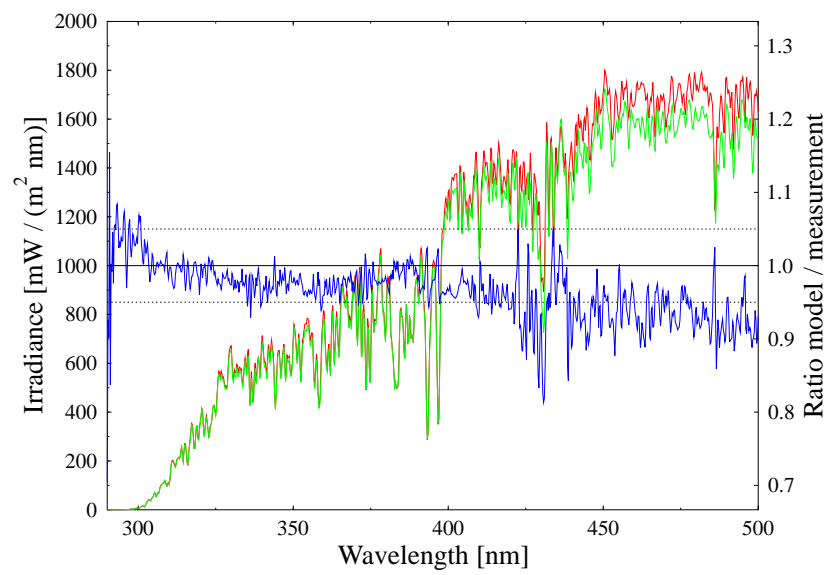

Fig. 8. The red line is the irradiance at 11:20 UTC, 5 August 2000, Nea Michaniona, Greece, as measured by a Bentham DTM 300 double monochromator spectroradiometer. In green is shown the uvspec simulation of the measured spectrum, while the blue curve is the model/measurement ratio.

2000). Cirrus clouds are typically composed of nonspherical ice crystals with various shapes and sizes. While the single scattering properties of water clouds are completely defined by the droplet size distribution and can be calculated with Mie theory, no equivalent straightforward solution is available for ice crystals. Both experimental and theoretical studies show that single scattering properties of non-spherical ice particles may differ substantially from those of surface- or volume-equivalent spheres, see e.g. Mishchenko et al. (1996) and references therein. Nevertheless, often the single scattering properties of these clouds have been calculated assuming spherical shapes of the ice crystals. This is partly due to the difficulty of computing single scattering properties of nonspherical particles. However, advances in solution methods, (Kahnert, 2003), and increasing computer power have made it possible to create parameterizations of scattering and absorption properties of individual ice crystals based on accurate light scattering calculations (Yang et al., 2000; Key et al., 2002). The uvspec model provides different parameterizations of ice cloud optical properties, as described in Sect. 2.3.3. In this example we compare the different parameterizations and their impact on the calculated solar flux. For the example we have chosen a homogeneous ice cloud between 9 and $10 \mathrm{~km}$. The ice water content (IWC) was varied between 0 and $0.1 \mathrm{~g} / \mathrm{cm}^{3}$ and the effective radius was $20 \mu \mathrm{m}$.

Figure 9 shows ice cloud optical properties as provided by two parameterizations included in uvspec. The solid blue line is a 56-band parameterization by Key et al. (2002) which uses a double Henyey-Greenstein approximation of the phase function that properly describes the forward and backward peak. It has been shown that this parameterization is even suited for the calculation of radiances, e.g. Gonzalez et al. (2002). Key et al. (2002) allows a choice of six different particle habits, and for this example we selected solid 

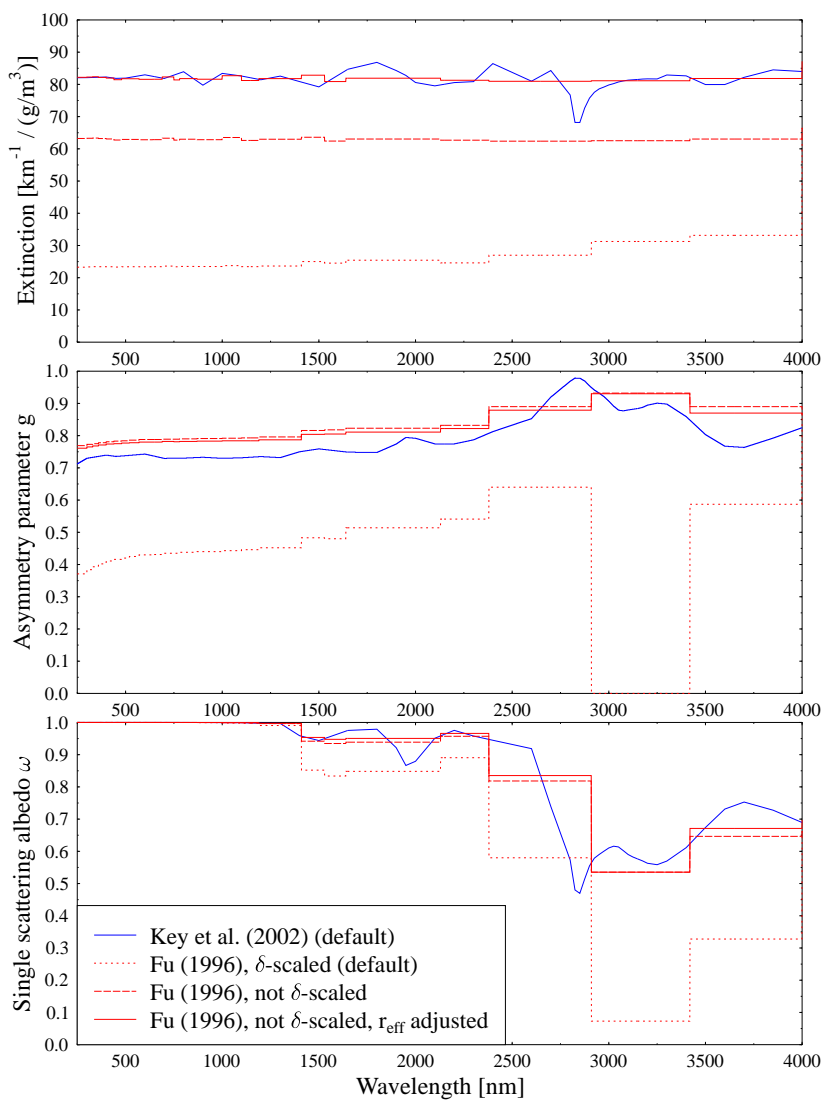

Fig. 9. Ice cloud optical properties from different parameterizations, for an effective particle size $20 \mu \mathrm{m}$ and solid (hexagonal) columns. Solid blue line: Key et al. (2002); dotted red line: Fu (1996) delta-scaled (default); dashed red line: Fu (1996) not deltascaled; solid red line: Fu (1996) not delta-scaled and with effective radius consistent to Key et al. (2002). (Top) Extincition coefficient; (middle) asymmetry parameter; (bottom) single scattering albedo.

(hexagonal) columns. The dashed red line is the parameterization by $\mathrm{Fu}$ (1996). The huge difference between both parameterizations is mostly explained by the fact that $\mathrm{Fu}$ (1996) use delta-scaled optical properties while Key et al. (2002) provide unscaled properties. Delta-scaling means a truncation of the forward peak which is added to the direct (transmitted) radiation, see $\mathrm{Fu}$ (1996) for details. In consequence, the phase function is much smoother and can be safely approximated by a Henyey-Greenstein phase function; and, the optical thickness, single scattering albedo, and asymmetry factor are reduced. The figure clearly shows that this reduction can be rather severe, e.g. a factor of about 3 for the optical thickness in the visible spectral range. While deltascaling is important for two-stream approximations or the four-stream method by Fu and Liou (1992), its relevance is smaller when the disort solver is chosen. First, disort is able to handle the phase function in full detail; second, disort does a delta-scaling internally anyway. In consequence, the radiation calculated by disort is only slightly affected by the delta-scaling, see Fig. 10: The blue line is again the parameterization by Key et al. (2002). By default, uvspec uses the delta-scaled optical properties by $\mathrm{Fu}$ (1996) as recommended there (dotted red line), but using an input parameter ic_fu_tau unscaled allows to switch delta-scaling off (dashed red line). If one defines a cloud only by its microphysical properties (ice water content, effective radius), delta-scaling should certainly be switched on. If one, however, uses the $\mathrm{Fu}$ (1996) parameterization in combination with an explicit definition of the optical thickness, asymmetry parameter, or single scattering albedo, it might be reasonable to switch delta-scaling off. This is a complicated and confusing topic and it is recommended that the user experiments with the options, reads the paper by Fu (1996), and makes heavy use of the verbose feature.

Even after switching off delta-scaling, large differences remain between the Key et al. (2002) and Fu (1996) parameterizations (Fig. 9): The reason is the use of different definitions of the effective radius by both authors. While for spherical droplets the effective radius is a clearly defined quantity, several different definitions of the effective radius exist for non-spherical particles (McFarquhar and Heymsfield, 1998). Careful evaluation of the formulas leads to the result that, for the same hexagonal particle, the effective radius would be $3 \sqrt{3} / 4=1.299$ times larger following the Key et al. (2002) definition than the $\mathrm{Fu}$ (1996) definition. Another option, ic_fu_reff yang, allows to use the effective radius definition of Key et al. (2002) in the Fu (1996) parameterization. This explains most of the remaining differences, see solid red lines in Figs. 9 and 10. The remaining difference in the irradiances is mostly caused by the asymmetry parameter. Key et al. (2002) use a double Henyey-Greenstein phase function with a small backward peak. This makes the asymmetry parameter somewhat smaller than in the $\mathrm{Fu}$ (1996) parameterization, causing more reflected and less transmitted irradiance.

\subsection{Inhomogeneous clouds (uvspec)}

Clouds are inherently inhomogeneous at all spatial scales. To treat this inhomogeneity properly, two things are required: First, a radiative transfer equation solver which allows to consider inhomogeneity, e.g. MYSTIC. Second, the threedimensional distribution of liquid water content and droplet or particle size. To demonstrate the treatment of inhomogeneous clouds in libRadtran we chose the second case of the Intercomparison of 3-D Radiation codes (Cahalan et al., 2005). The two-dimensional cloud field is based on extinction retrievals from the MMCR (Millimeter Cloud Radar) and the MWR (microwave radiometer) at the ARM CART site in Oklahoma on 8 February 1998. The field consists of 640 columns along the $\mathrm{x}$-direction, which were set to have a $50 \mathrm{~m}$ horizontal width (for the $10 \mathrm{~s}$ measurements this corresponds to the observed wind speed of $\sim 5 \mathrm{~m} / \mathrm{s}$ ), and each column is resolved into 54 vertical layers which are $45 \mathrm{~m}$ thick (z-direction). It is assumed that the cloud is infinite 


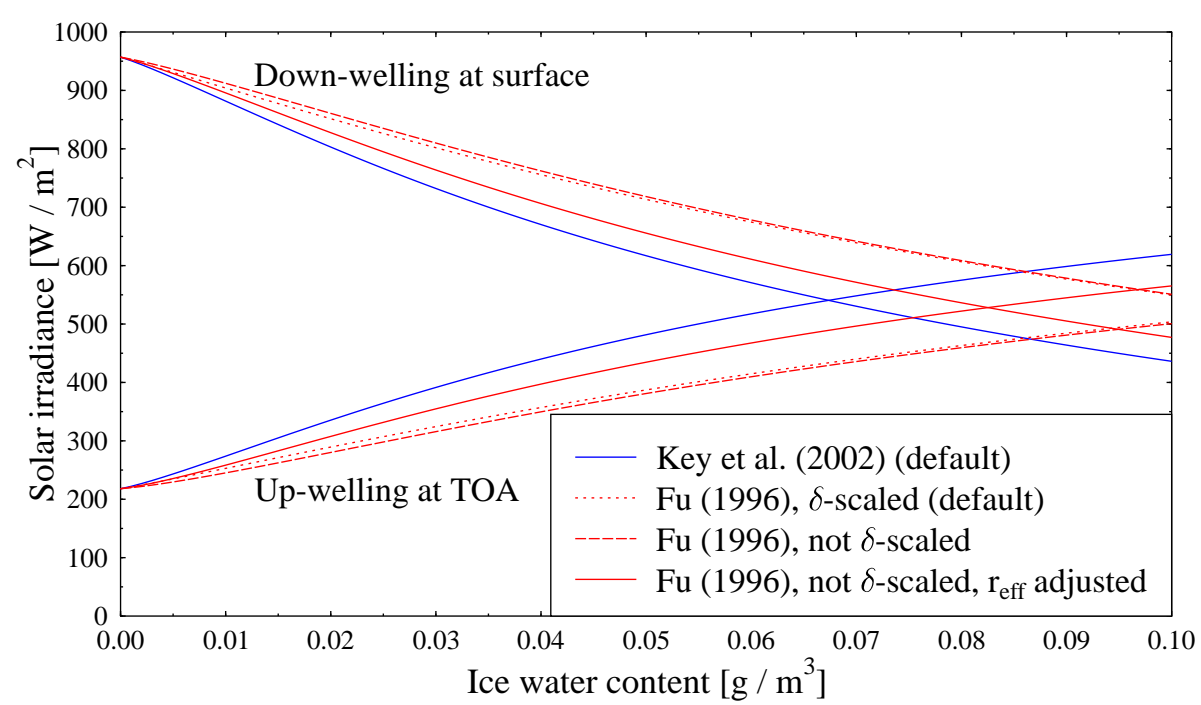

Fig. 10. Reflected and transmitted solar irradiance using the optical properties from Fig. 9. The line styles and colors are equal to Fig. 9; an ice water content of 0.1 corresponds to a visible optical thickness of about 8 .

along the y-direction. In deviation from the original data set some inhomogeneity was added by cutting off the optically thin regions: Columns with an integrated optical thickness of less than 10 were declared cloudless which resulted in a cloud cover of 82\%, see top and middle panels of Fig. 11.

For simplicity, the asymmetry parameter was set to a constant value of 0.85 and a single scattering albedo of 1 was assumed which are reasonable assumptions for the visible spectral range. To isolate the cloud-radiation interaction, the background molecular atmosphere was switched off using no_rayleigh and no_molecular_absorption. The solar zenith angle was $30^{\circ}$ with the sun shining from the left side. The bottom plot of Fig. 11 compares the results of three methods to calculate the transmittance at cloud bottom, $\mathrm{z}=0.6 \mathrm{~km}$. The most accurate yet most time-consuming calculation is the three-dimensional Monte Carlo (MYSTIC) calculation which gives to our knowlegde exact results (blue curve). Indeed, for this simple case, 13 out of 16 contributing models (including MYSTIC) agreed within $\pm 0.5 \%$ in the Intercomparison of 3-D radiation codes (Cahalan et al., 2005). In comparison, the red curve shows the independent pixel approximation which involves 640 calls to DISORT2, one for each individual cloud column, using wc_ipa_files. Comparing both results, a few typical three-dimensional features become obvious. First, the independent pixel approximation resembles the variations of the optical thickness distribution much closer than the three-dimensional simulation. The much smoother variation of the radiation field in the exact calculation is caused by net horizontal photon diffusion which results in so-called "radiative smoothing" (Marshak et al., 1995). Second, in the cloud gaps, the transmittance might be considerably enhanced compared to the theoretical cloudless value $T_{\text {cloudless }}=\cos \left(30^{\circ}\right)=0.86603$. Actually, the maximum calculated value is 1.48 which is $70 \%$ higher than the independent pixel maximum of 0.86603 . Finally, the transmittance field is shifted away from the sun compared to the optical thickness distribution which is clearly again a result of net horizontal photon transport. Despite these effects which are not correctly reproduced by the independent pixel approximation, the area averages are surprisingly close. While the correct MYSTIC transmittance is 0.412 , the independent pixel approximation gives 0.414 which is only $0.5 \%$ higher. It has been shown that the independent pixel approximation may give quite correct results for the averaged transmittance or reflection, in particular for overcast conditions (Cahalan et al., 1994a,b), although possibly for the wrong reason as the detailed analysis above has shown. In real applications, however, the detailed distribution of optical properties is often not known in which case a much simpler approximation is required. One example is shown, using wc_cloudcover $\mathbf{0 . 8 2 3 4 4}$. With this option, only two independent calculations are done, for a clear column and a cloudy column using the average extinction coefficient profile over all cloudy columns. Using this fast approximation which requires only little knowledge of the actual cloud structure a cloudless transmittance of 0.86603 and a cloud transmittance of 0.28599 are obtained (green curve in Fig. 11). The cloudcover-weighted average returned by libRadtran is 0.388 which is $6 \%$ lower than the correct three-dimensional result. The deviation which is due to the cloudy fraction only is the so-called plane-parallel bias, a systematic over-estimation of the reflection and under-estimation of the transmittance when the variability of the cloud properties is neglected (Cahalan et al., 1994a). This example is by no means extreme, and larger as well as smaller differences between the three approaches may be obtained depending on cloud geometry as well as solar zenith angle. 

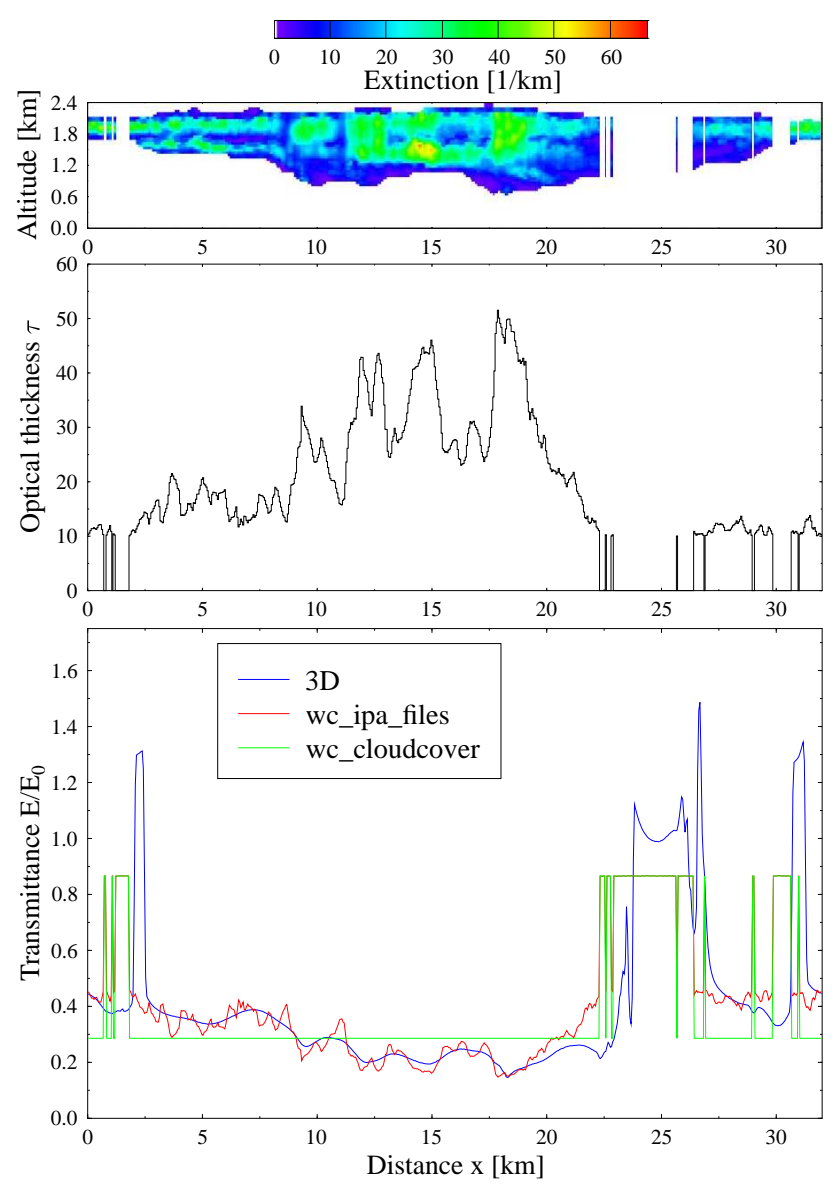

Fig. 11. (Top) Extinction coefficient on a vertical cross section through the cloud. (Middle) Vertically integrated optical thickness. (Bottom) Transmittance at cloud bottom $(0.6 \mathrm{~km})$ : Threedimensional MYSTIC simulation (blue), independent pixel approximation (red), cloud-cover approximation (green). Transmittance is defined as the ratio of transmitted irradiance $E$ divided by the extraterrestrial irradiance $E_{0}$.

4.5 Ozone, clouds, and doserates (Gen_o3_tab.pl, Gen_wc_tab.pl, read_o3_tab)

Spectral information may be used to derive information about the state of the atmosphere. Stamnes et al. (1991) proposed methods to derive the ozone column and the cloud optical thickness from measured UV spectra. This method was subsequently adopted to multichannel moderate bandwidth filter instruments by Dahlback (1996). Tools for generation of the necessary lookup tables are included within libRadtran. Gen_03_tab.pl generates lookup tables for the retrieval of the ozone column from downwelling irradiance or zenith radiance ratios. The ratios are made of radiation from one wavelength or wavelength interval that is sensitive to ozone absorption and one that has low sensitivity. The lookup table of the total ozone column is a function of the solar zenith angle and the ratio. Similarily Gen_wc_tab.pl generates lookup tables for estimation of effective cloud optical thickness and/or sky transmittance from global irradiance measurements at a single wavelength or wavelength interval. By effective cloud optical thickness is meant the optical thickness that, when used as input to the model, best reproduces the measurements. Hence, the effective cloud optical thickness includes both aerosol and cloud contributions. The lookup tables are read by the read_o3_tab program that returns the total ozone column or cloud information depending on the lookup table and additional input information.

Examples of the use of these tools are provided in Fig. 12.

The CIE doserate (McKinlay and Diffey, 1987) as derived from a Ground-based Ultraviolet Radiometer (GUV541, Biospherical Instruments Inc., San Diego, USA) multichannel moderate bandwidth filter instrument is shown in black. The CIE dose at noon is the basis for deriving the UVindex (International Commision on Non-Ionizing Radiation Protection, 1995). Data are from Julian day 172 (21 June 1997), Troms $\varnothing$, Norway and are shown at one minute resolution. Both the measurements and the methods become less reliable at large solar zenith angle, thus results shown are for solar zenith angles smaller than $80^{\circ}$.

Between 04:00 and 09:00 the sky was cloudless. This is reflected both in the CIE doserate and the cloud optical thickness, the latter being zero for this time interval. Around noon some clouds start to appear. The clouds are broken and occasionally cause CIE doserates higher than the corresponding cloudless values. In the afternoon the clouds get slightly denser with optical thickness between 1.5 and 11 .

The ozone column average over the day is $(369 \pm 13)$ DU. Some variations are seen in the derived column. Some are due to uncertainties associated with the method and the measurements. For example for large solar zenith angles the lookup table is sensitive to the ozone profile. Also some cloud influence is evident. Mayer et al. (1998) described that enhanced absorption of UV radiation may take place due to multiple scattering in clouds. This may lead to unrealistically large ozone columns with this method for ozone retrieval. Thus, it is customary to ignore ozone values for large cloud optical thickness.

Some of these methods have been used by for example Leontyeva and Stamnes (1994); Leontyeva et al. (1994); Barker et al. (1998) and Kylling et al. (2000) to study the effect of clouds on the radiation field. Finally it is noted that Bernhard et al. (2003) have developed an improved method to derive the total ozone column from global UV spectra using uvspec.

\subsection{Angular response and tilted surfaces (uvspec, angres)}

UV radiation is typically measured on a horizontal surface. However, for many applications it is of interest to know the incoming radiation on surfaces of any orientation. For a given atmospheric situation, the uvspec tool may be used to calculate the radiance field. To obtain the radiation quantity 


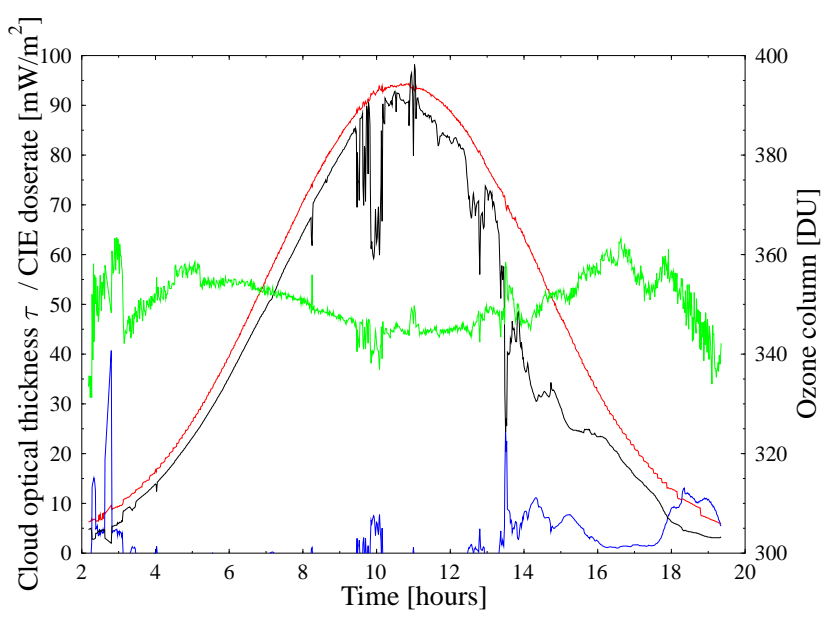

Fig. 12. The CIE doserate, black line, derived from a GUV multichannel moderate bandwidth filter instrumeent. The instrument was located in Troms $\varnothing$, Norway, $69.95^{\circ} \mathrm{N}, 18.95^{\circ} \mathrm{E}, 65 \mathrm{~m}$ a.s.l. The measurements are for 21 June 1997. The cloudless CIE doserate as calculated by uvspec is shown in red. The total ozone column and cloud optical thickness derived from the GUV measurements are shown in green and blue, respectively.

of interest the angres tool may subsequently be used to integrate the radiance field over a specified angular area using any angular response. The NILU-CUBE instrument measures the irradiance on the six faces of a cube in two channels centered approximately at 312 and $340 \mathrm{~nm}$ (Kylling et al., 2003a). During the ADMIRA campaign in August 2000 at Nea Michaniona, Greece (Webb et al., 2002), the NILUCUBE was mounted about $3 \mathrm{~m}$ above a roof with one head pointing up, one down, and the others to the east, south, west and north. Thus, the NILU-CUBE measured the down- and upwelling irradiances in addition to the irradiance on the vertical detector heads facing east, south, west and north. The measured irradiances are shown as solid lines in Fig. 13 for 5 August 2000. The measurements have been simulated by first using uvspec to obtain the radiance fields. The input to uvspec is similar to that used in Sect. 4.2 with one important exception. In this example the spectrum must be integrated over the bandpass of the two channels. This is easily achieved by specifying the spectral response of the channels using the filter_function_file option and integrating over the bandpass with the output integrate option. The resulting radiance fields have been integrated by the angres tool over the appropriate solid angle using the measured angular response of the NILU-CUBE instrument. The resulting model simulations are shown as dashed lines in Fig. 13. The model simulations clearly reproduce the main features of the measurements. It is interesting to note that for $340 \mathrm{~nm}$ for these particular measurements, the maximum irradiances for the east and west facing detectors are larger than the maximum value for the south facing detector.

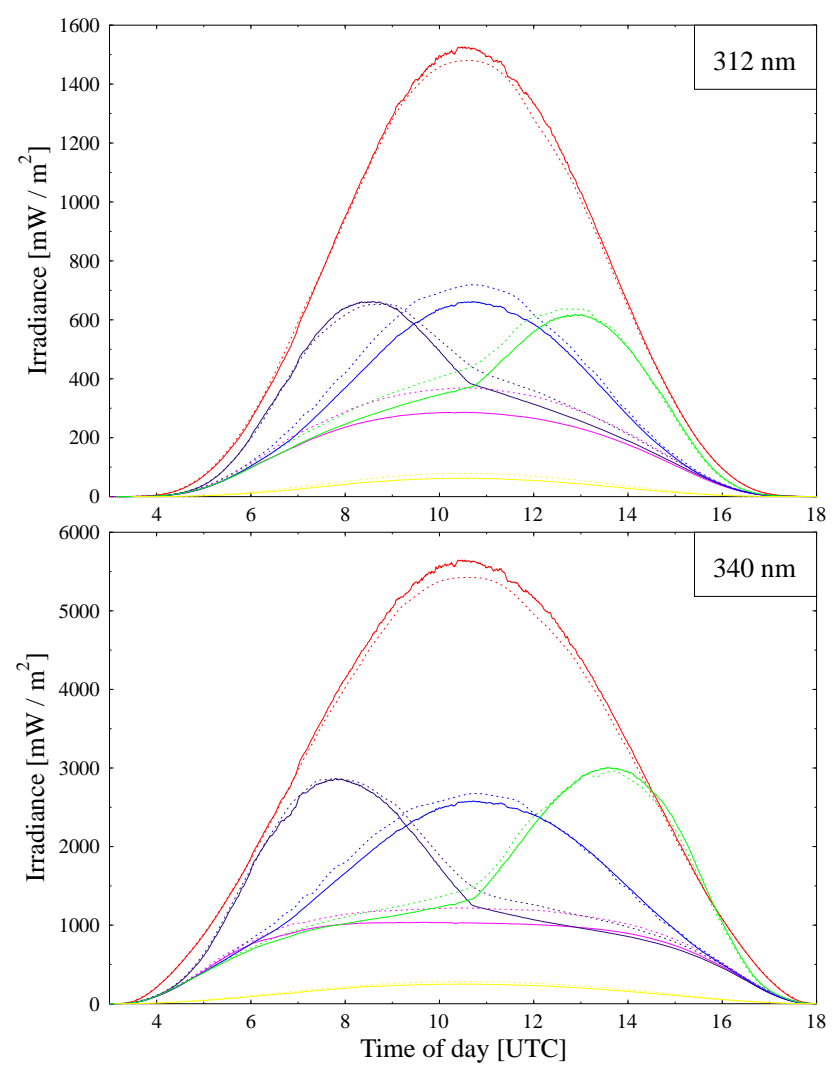

Fig. 13. Measured (solid) and simulated (dashed) NILU-CUBE irradiances as a function of time. The measurements were made on 5 August 2000, at Nea Michaniona, Greece, as part of the ADMIRA project (Webb et al., 2002). The downwelling irradiance is shown in red, the upwelling in yellow. The magenta, blue, green and purple colored lines represent the vertical east, south, west and north irradiances, respectively.

\subsection{Radiances (uvspec)}

Angular resolved radiances are required for a variety of purposes, the most important probably being the remote sensing of cloud and aerosol parameters from space. uvspec is heavily used for such calculations, see e.g. Mayer et al. (2004); Gonzalez et al. (2002). Here we present the sky radiance at the ground, to highlight the ability of the model to handle strongly peaked scattering phase functions. Figure 14 presents the sky radiance as a function of zenith angle in the solar principle plane. The upper plot is a uvspec calculation for a pure Rayleigh atmosphere, without aerosol. The solar zenith angle was set to $30^{\circ}$ as indicated in the plot. A typical feature of the Rayleigh atmosphere is the horizon brightening which is well-known from observations, see e.g. Huber et al. (2004). These calculations were done with the DISORT 2.0 solver, neglecting the influence of polarization. As has been shown by Mishchenko et al. (1994) this may introduce an uncertainty of up to about $10 \%$; the maximum error occurs 

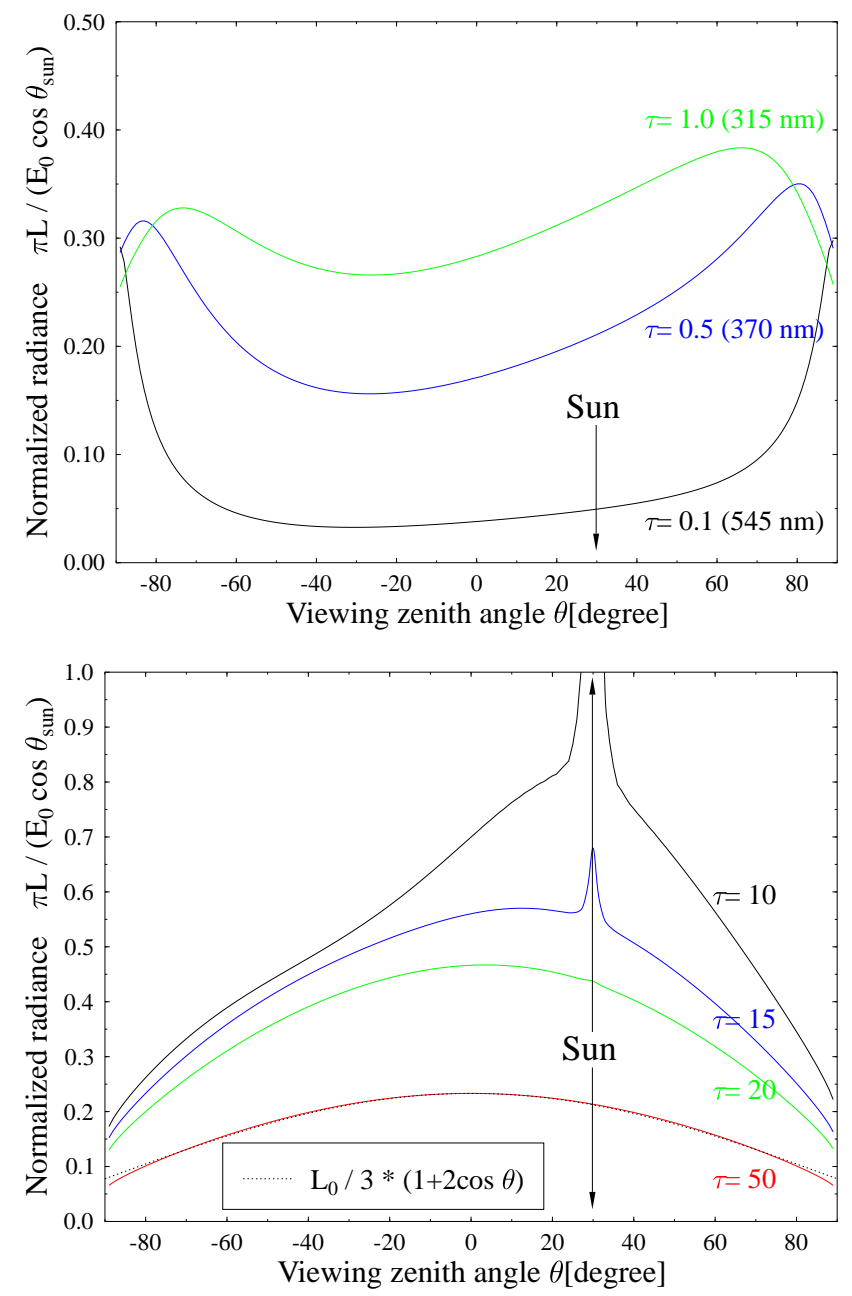

Fig. 14. Sky radiance distribution in the solar principle plain. The location of the sun at $\theta_{\text {sun }}=30^{\circ}$ is marked. (Top) Rayleigh atmosphere. (Bottom) Cloudy atmosphere.

for optical thickness around 1 which is typical for Rayleigh scattering in the ultraviolet- $\mathrm{B}$ range.

In presence of clouds, the angular distribution looks completely different, see lower panel in Fig. 14. For optically thin clouds, a strong forward peak occurs towards the direction of the sun. This narrow cone of scattered radiation is due to the highly peaked scattering phase function of water clouds, see Fig. 6. To adequately resolve such structures of the scattering phase function, like the forward scattering peak, the rainbow, or the glory, one needs to use a large number of computational angles in DISORT 2, in our case nstr 256. Mayer et al. (2004) showed that very good agreement with observations can be obtained, even for such complex applications. The default number of computational angles in uvspec is 16 for the calculation of radiances which is enough for most applications. The bottom plot of Fig. 14 shows another interesting feature of clouds: With increasing optical thickness the forward peak vanishes and the angular distri- bution reaches a distribution which carries no indication of the direction of the sun and is essentially independent of solar zenith angle. The dotted line is a very simple analytical formula which closely fits the data:

$L(\theta)=L_{0} / 3 \cdot(1+2 \cos \theta)$,

where $\theta$ is the viewing zenith angle and $L_{0}=L(\theta=0)$ is the radiance in nadir direction. This is also a well-known result, both theoretically (e.g. Sobolev, 1975) and experimentally (e.g. Grant and Heisler, 1997; Kuchinke et al., 2004). Equation (7) clearly shows that the sky radiance under overcast conditions is non-isotropic and reaches its maximum in the zenith direction.

\subsection{Airmass factor calculations (airmass.pl)}

One technique to measure concentrations of atmospheric trace-gases is differential optical absorption spectroscopy (DOAS), see Marquard et al. (2000) and references therein. The DOAS method allows the slant column density of a variety of species to be measured. The slant column density varies with solar zenith angle and detector viewing angles. To be able to compare measurements for different viewing geometries, the slant column measurements must be converted to vertical column densities. This is done with the use of the so-called airmass factor. For an absorbing species the airmass factor, $A$, is defined as the ratio of the slant column density, $S$, of this absorber to its vertical density, $V$. For a zenith viewing instrument the airmass is traditionally calculated as (Marquard et al., 2000)

$A=S / V=\frac{\ln L^{\prime} / \ln L}{\sigma V}$.

Here $L$ and $L^{\prime}$ are the zenith radiances with and without the absorber, respectively. The absorption cross section of the absorber, $\sigma$, is the same used when calculating $L^{\prime}$. The slant column is

$S=\frac{\ln L^{\prime} / \ln L}{\sigma}$.

The airmass.pl tool may readily be used to calculate the airmass factor and the slant column for a number of atmospheric species. As uvspec input may be directly specified in the airmass.pl tool, it is also an excellent tool for sensitivity tests of airmass factor calculations. Figure 15 shows as a function of the solar zenith angle the $\mathrm{NO}_{2}$ slant column and how it depends on the $\mathrm{NO}_{2}$ profile used in the calculation. The concentration of $\mathrm{NO}_{2}$ varies rapidly around twilight due to photolysis. This implies that photons encounter different $\mathrm{NO}_{2}$ profiles as they traverse the atmosphere (Solomon et al., 1987). The shape of the profile may have a significant effect on the airmass factor and slant column density calculations as exemplified with the daytime (red line) and nighttime (green line) profile slant column densities in Fig. 15. Thus this solar 


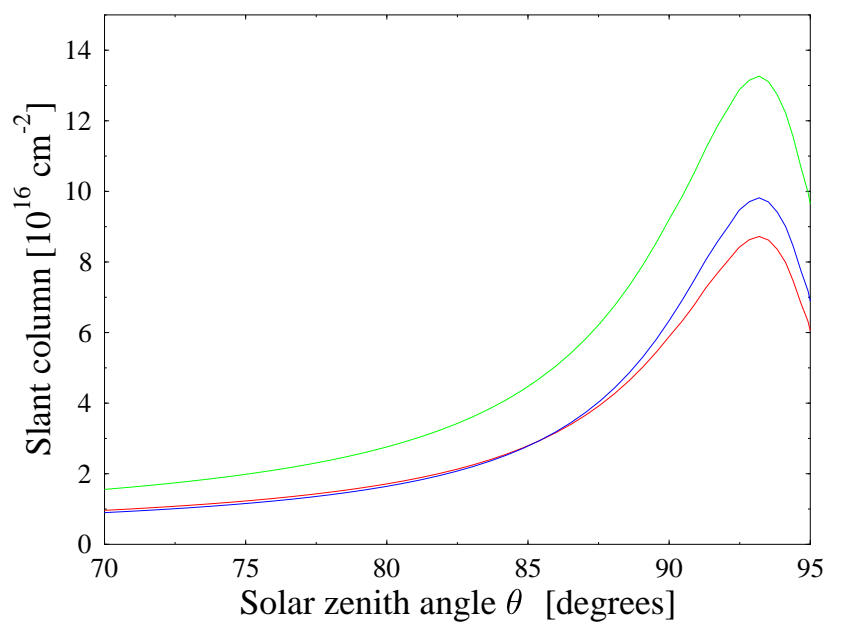

Fig. 15. The $\mathrm{NO}_{2}$ slant column for a day time $\mathrm{NO}_{2}$ profile (red line), night time profile (green line) and using the option to the sdisort solver that accounts for chemical conversion (blue line).

zenith angle dependent variation in the profile of the absorbing species must be accounted for. The solver sdisort allows as input a two-dimensional matrix of the density of the absorbing species as a function of altitude and solar zenith angle. With this approach the direct beam is calculated in 2-D geometry while the diffuse radiation is calculated in pseudospherical geometry. This allows the chemical conversion of $\mathrm{NO}_{2}$ around twilight to be accounted for in the calculation. The effect is significant as shown with the blue line in Fig. 15.

It is noted that the altitude resolution, or layering of the atmosphere, may be important for airmass factor calculations. If the input is at say $1 \mathrm{~km}$ vertical resolution, it may readily be changed to finer resolution by the altitude option. For example altitude 00.25 implies that the atmosphere starts at $0.0 \mathrm{~km}$ and the vertical resolution of the atmosphere will be recalculated to $0.25 \mathrm{~km}$.

The airmass.pl tool may also readily be used for other viewing directions, including both nadir viewing aircraft and satellite instruments and off-axis DOAS measurements. The latter is increasingly taken in use both for ground based and airborne platforms (Sanders et al., 1993; Arpag et al., 1994; Hönninger and Platt, 2002; Petritoli et al., 2002; Wittrock et al., 2004). While zenith sky measurements are predominantly sensitive to stratospheric densities, off-axis DOAS are sensitive to trace gases near the surface. Off-axis DOAS also has the potential of providing information on the vertical distribution of trace gases.

\section{Installation of libRadtran}

The libRadtran package includes a detailed description on how to compile and install the software on various flavors of the Unix operating system and various Windows versions. A configuration script automagically sets up system dependent compiler options. The main tool of libRadtran, uvspec, is partly written in C and Fortran. With this tool and all other tools in the package, every effort has been made to make sure that the software compiles and runs on freely available software. The development of libRadtran is done under Linux but the package has been shown to run under various UNIXes including Solaris, under Macintosh OSX, and under various Microsoft Windows systems.

\section{Conclusions}

The libRadtran software package has been described and examples have been given of its use. The package is a comprehensive, powerful, user-friendly and well documented collection of tools for radiative transfer calculations in the Earth's atmosphere. The main tool is the versatile uvspec radiative transfer model. It may readily handle anything from simple educational tasks to advanced research problems.

The libRadtran software package is the fruits of about 10 years of collaboration between the authors. Several colleagues have contributed with comments, corrections and software. As such, the libRadtran software package is under continuous development. The libRadtran software package is available from http://www.libradtran.org.

Acknowledgements. Numerous colleagues have contributed with comments and software to libRadtran. We would like to thank K. Stamnes, W. Wiscombe, S.-C. Tsay, and K. Jayaweera (disort); F. Evans (polradtran); S. Kato (correlated- $k$ distributions); J.-M. Vandenberghe, F. Hendrick, and M. V. Roozendael (sdisort); T. Charlock, Q. Fu and F. Rose (Fu and Liou code); D. Kratz (AVHRR routines); A. Gonzales (included ice crystal parameterization); J. Key and P. Yang (ice cloud tables); P. Ricchiazzi (LOWTRAN/SBDART gas absorption), L. Bugliaro (TZS solver); O. Engelsen (implementation of ozone cross sections). Numerous feedback and contributions from users have improved the software over the years. Thanks to you all. Thanks also goes to M. Blumthaler for allowing us to use his measurements of global and direct irradiances for the example in Sect. 4.2. Finally we want to thank G. Bernhard for carefully reading the manuscript!

Edited by: A. Hofzumahaus

\section{References}

Anderson, G., Clough, S., Kneizys, F., Chetwynd, J., and Shettle, E.: AFGL atmospheric constituent profiles $(0-120 \mathrm{~km})$, Tech. Rep. AFGL-TR-86-0110, Air Force Geophys. Lab., Hanscom Air Force Base, Bedford, Mass., 1986.

Arpag, K. H., Johnston, P. V., Miller, H. L., Sanders, R. W., and Solomon, S.: Observations of the stratospheric BrO column over Colorado, 40 N, J. Geophys. Res., 99, 8175-8181, 1994.

Bais, A. F., Madronich, S., Crawford, J., Hall, S. R., Mayer, B., van Weele, M., Lenoble, J., Calvert, J. G., Cantrell, C. A., Shetter, R. E., Hofzumahaus, A., Koepke, P., Monks, P. S., Frost, G., McKenzie, R., Krotkov, N., Kylling, A., Swartz, W. H., Lloyd, 
S., Pfister, G., Martin, T. J., Roeth, E.-P., Griffioen, E., Ruggaber, A., Krol, M., Kraus, A., Edwards, G. D., Mueller, M., Lefer, B. L., Johnston, P., Schwander, H., Flittner, D., Gardiner, B. G., Barrick, J., and Schmitt, R.: International Photolysis Frequency Measurement and Model Intercomparison (IPMMI): Spectral actinic solar flux measurements and modeling, J. Geophys. Res., 108, doi:10.1029/2002JD002891, 2003.

Barker, H. W., Curtis, T. J., Leontieva, E., and Stamnes, K.: Optical depth of overcast cloud across Canada: estimates based on surface pyranometer and satellite measurements, J. Climate, 11, 2980-2994, 1998.

Bass, A. M. and Paur, R. J.: The ultraviolet cross-section of ozone, I, The measurements, in: Atmospheric Ozone: Proceedings of the Quadrennial Ozone Symposium, edited by: Zerefos, C. S. and Ghazi, A., D. Reidel, Norwell, Mass., 601-606, 1985.

Bernhard, G. and Seckmeyer, G.: Uncertainty of measurements of spectral solar UV irradiance, J. Geophys. Res., 104, 1432114 345, 1999.

Bernhard, G., Booth, C. R., and McPeters, R. D.: Calculation of total column ozone from global UV spectra at high latitudes, J. Geophys. Res., 108, doi:10.1029/2003JD003450, 2003.

Blanco-Muriel, M., Alarcón-Padilla, D. C., López-Moratella, T., and Lara-Coira, M.: Computing the solar vector, Solar Energy, 70, 431-441, 2001.

Bodhaine, B. A., Wood, N. B., Dutton, E. G., and Slusser, J. R.: On Rayleigh optical depth calculations, J. Atm. Ocean Technol., 16, 1854-1861, 1999.

Burrows, J. P., Dehn, A., Deters, B., Himmelmann, S., Richter, A., Voigt, S., and Orphal, J.: Atmospheric remote-sensing reference data from GOME: Part 1. Temperature-dependent absorption cross sections of $\mathrm{NO}_{2}$ in the 231-794 nm range, J. Quant. Spectrosc. Radiat. Transfer, 60, 1025-1031, 1998.

Cahalan, R., Ridgway, W., Wiscombe, W., and Bell, T.: The albedo of fractal stratocumulus clouds, J. Atmos. Sci., 51, 2434-2455, 1994a.

Cahalan, R., Ridgway, W., Wiscombe, W., Gollmer, S., and Harshvardhan: Independent pixel and Monte Carlo estimates of stratocumulus albedo, J. Atmos. Sci., 51, 3776-3790, 1994b.

Cahalan, R., Oreopoulos, L., Marshak, A., Evans, K., Davis, A., Pincus, R., Yetzer, K., Mayer, B., Davies, R., Ackerman, T.P., Barker, H.W., Clothiaux, E.E., Ellingson, R.G., Garay, M.J., Kassianov, E., Kinne, S., Macke, A., O'Hirok, W., Partain, P.T., Prigarin, S.M., Rublev, A.N., Stephens, G.L., Szczap, F., Takara, E.E., Varnai, T., Wen, G. and Zhuraleva, T.B.: The International Intercomparison of 3-D Radiation Codes (I3RC): Bringing together the most advanced radiative transfer tools for cloudy atmospheres, Bulletin of the American Meteorological Society, in press, 2005.

Cantrell, C. A., Davidson, J. A., McDaniel, A. H., Shetter, R. E., and Calvert, J. G.: Temperature-dependent formaldehyde cross sections in the near-ultraviolet spectral region, J. Chem. Phys., 94, 3902-3908, 1990.

Chandrasekhar, S.: Radiative Transfer, Dover, Mineola, N. Y., 1960.

Cox, C. and Munk, W.: Measurement of the roughness of the sea surface from photographs of the sun's glitter, Journal of the Optical Society of America, 44, 838-850, 1954a.

Cox, C. and Munk, W.: Statistics of the sea surface derived from sun glitter, J. Marine Res., 13, 198-227, 1954b.
Cox, R. A., Sheppard, D. W., and Stevens, M. P.: Absorption coefficients and kinetics of the $\mathrm{BrO}$ radical using molecular modulation, J. Photochem., 19, 189-207, 1982.

Dahlback, A.: Measurements of biologically effective UV doses, total ozone abundances, and cloud effects with multichannel, moderate bandwidth filter instruments, Appl. Opt., 35, 6514-6521, 1996.

Dahlback, A. and Stamnes, K.: A new spherical model for computing the radiation field available for photolysis and heating at twilight, Planet. Space Sci., 39, 671-683, 1991.

DeBacker, H., Koepke, P., Bais, A., de Cabo, X., Frei, T., Gillotay, D., Haite, C., Heikkilä, A., Kazantzidis, A., Koskela, T., Kyrö, E., Lapeta, B., Lorente, J., Masson, K., Mayer, B., Plets, H., Redondas, A., Renaud, A., Schauberger, G., Schmalwieser, A., Schwander, H., and Vanicek, K.: Comparison of measured and modelled UV indices, Meteorological Applications, 8, 267-277, 2001.

Edwards, D. P.: GENLN2: A general line-by-line atmospheric transmittance and radiance model: Version 3.0 description and users guide, National Center for Atmospheric Research (NCAR), NCAR/TN-367+STR, Boulder, Colorado, 1992.

Evans, K.: The spherical harmonics discrete ordinate method for three-dimensional atmospheric radiative transfer, J. Atmos. Sci., 55, 429-446, 1998.

Evans, K. F. and Stephens, G. L.: A new polarized atmospheric radiative transfer model, J. Quant. Spectrosc. Radiat. Transfer, 46, 413-423, 1991.

Forster, P. M. D. F., Shine, K. P., and Webb, A. R.: Modelling ultaviolet radiation at the Earth's surface, Part II: Model and Instrument Comparison, J. Appl. Meteorology, 34, 2426-2439, 1995.

$\mathrm{Fu}, \mathrm{Q}$.: An accurate parameterization of the solar radiative properties of cirrus clouds for climate models, J. Climate, 9, 20582082, 1996.

Fu, Q. and Liou, K.: On the correlated k-distribution method for radiative transfer in nonhomogeneous atmospheres, J. Atmos. Sci., 49, 2139-2156, 1992.

Fu, Q., Yang, P., and Sun, W. B.: An accurate parameterization of the infrared radiative properties of cirrus clouds for climate models, J. Climate, 11, 2223-2237, 1998.

Gonzalez, A., Wendling, P., Mayer, B., Gayet, J.-F., and Rother, T.: Remote sensing of cirrus cloud properties in the presence of lower clouds: An ATSR-2 case study during the Interhemispheric Differences in Cirrus Properties From Anthropogenic Emissions (INCA) experiment, J. Geophys. Res., 107, doi:10.1029/2002JD002535, 2002.

Grant, R. and Heisler, G.: Obscured overcast sky radiance distributions for ultraviolet and photsyntetically active radiation, J. Appl. Meteorology, 36, 1336-1345, 1997.

$\mathrm{Gu}$, Y. and Liou, K. N.: Interactions of radiation, microphysics, and turbulence in the evolution of cirrus clouds, J. Atmos. Sci., 57, 2463-2479, 2000.

Gueymard, C.: The sun's total and spectral irradiance for solar energy applications and solar radiation models, Solar energy, 76, 423-453, 2003.

Hofzumahaus, A., Kraus, A., Kylling, A., and Zerefos, C.: Solar actinic radiation $(280-420 \mathrm{~nm})$ in the cloud-free troposphere between ground and $12 \mathrm{~km}$ altitude: Measurements and model results, J. Geophys. Res., 107, doi:10.1029/2001JD900142, 2002. 
Hofzumahaus, A., Lefer, B. L., Monks, P. S., Hall, S. R., Kylling, A., Shetter, B. M. R. E., Junkermann, W., Bais, A., Calvert, J. G., Cantrell, C. A., Madronich, S., Edwards, G. D., Kraus, A., Müller, M., Bohn, B., Schmitt, R., Johnston, P., McKenzie, R., Frost, G. J., Griffioen, E., Krol, M., Martin, T., Pfister, G., Röth, E. P., Ruggaber, A., Swartz, W. H., Lloyd, S. A., and Van Weele, M.: Photolysis frequency of $\mathrm{O}_{3}$ to $\mathrm{O}\left({ }^{1} \mathrm{D}\right)$ : Measurements and modeling during the International Photolysis Frequency Measurement and Modeling Intercomparison (IPMMI), J. Geophys. Res., 109, D08S90, doi:10.1029/2003JD004333, 2004.

Hönninger, G. and Platt, U.: Observations of $\mathrm{BrO}$ and its vertical distribution during surface ozone depletion at Alert, Atmos. Envir., 36, 2481-2489, 2002.

$\mathrm{Hu}, \mathrm{Y} . \mathrm{X}$. and Stamnes, K.: An accurate parameterization of the radiative properties of water clouds suitable for use in climate models, J. Climate, 6, 728-742, 1993.

Huber, M., Blumthaler, M., Ambach, W., and Staehelin, J.: Total atmospheric ozone determined from spectral measurements of direct solar UV irradiance, Geophys. Res. Lett., 22, 53-56, 1995.

Huber, M., Blumthaler, M., Schreder, J., Schallhart, B., and Lenoble, J.: Effect of inhomogeneous surface albedo on diffuse UV sky radiance at a high-altitude site, J. Geophys. Res., 109, doi:10.1029/2003JD004113, 2004.

I3RC: Intercomparison of 3D Radiation Codes (I3RC), http://i3rc. gsfc.nasa.gov, 1999.

International Commision on Non-Ionizing Radiation Protection: Global Solar UV Index, ISBN 3-9804789-0-4, 1995.

Kahnert, F. M.: Numerical methods in electromagnetic scattering theory, J. Quant. Spectrosc. Radiat. Transfer, 79-80, 775-824, 2003.

Kato, S., Ackerman, T. P., Mather, J. H., and Clothiaux, E.: The $k$-distribution method and correlated- $k$ approximation for a shortwave radiative transfer model, J. Quant. Spectrosc. Radiat. Transfer, 62, 109-121, 1999.

Key, J. R., Yang, P., Baum, B. A., and Nasiri, S. L.: Parameterization of shortwave ice cloud optical properties for various particle habits, J. Geophys. Res., 107, doi:10.1029/2001JD000742, 2002.

Koepke, P., Bais, A., Balis, D., Buchwitz, M., DeBacker, H., de Cabo, X., Eckert, P., Eriksen, P., Gillotay, D., Heikkilä, A., Koskela, T., Lapeta, B., Litynska, Z., Lorente, J., Mayer, B., Rennaud, A., Ruggaber, A., Schauberger, G., Seckmeyer, G., Seifert, P., Schmalwieser, A., Schwander, H., Vanicek, K., and Weber, M.: Comparison of models used for UV index calculations, Photochemistry and Photobiology, 67, 657-662, 1998.

Kratz, D. P. and Varanasi, P.: The correlated k-distribution technique as applied to the AVHRR channels, J. Quant. Spectrosc. Radiat. Transfer, 53, 501-517, 1995.

Kuchinke, C., Fienberg, K., and Nunez, M.: The angular distribution of UV-B sky radiance under cloudy conditions: A comparison of measurements and radiative transfer calculations using a fractal model, J. Appl. Meteorology, 43, 751-761, 2004.

Kurucz, R.: Synthetic infrared spectra, in Proceedings of the 154th Symposium of the International Astronomical Union (IAU); Tucson, Arizona, March 2-6, 1992, Kluwer, Acad., Norwell, MA, 1992.

Kylling, A., Stamnes, K., Meier, R. R., and Anderson, D. E.: The 200- to 300-nm radiation field in the stratosphere: Comparison of models with observations, J. Geophys. Res., 98, 2741-2745, 1993.
Kylling, A., Stamnes, K., and Tsay, S.-C.: A reliable and efficient two-stream algorithm for spherical radiative transfer: documentation of accuracy in realistic layered media, J. Atmos. Chem., 21, 115-150, 1995.

Kylling, A., Bais, A. F., Blumthaler, M., Schreder, J., Zerefos, C. S., and Kosmidis, E.: The effect of aerosols on solar UV irradiances during the Photochemical Activity and Solar Ultraviolet Radiation campaign, J. Geophys. Res., 103, 26 051-26 060, 1998.

Kylling, A., Dahlback, A., and Mayer, B.: The effect of clouds and surface albedo on UV irradiances at a high latitude site, Geophys. Res. Lett., 27, 1411-1414, 2000.

Kylling, A., Danielsen, T., Blumthaler, M., Schreder, J., and Johnsen, B.: Twilight tropospheric and stratospheric photodissociation rates derived from balloon borne radiation measurements, Atmos. Chem. Phys., 3, 377-385, 2003a,

SRef-ID: 1680-7324/acp/2003-3-377.

Kylling, A., Webb, A. R., Bais, A. F., Blumthaler, M., Gobbi, G.-P., Schmitt, R., Thiel, S., Barnaba, F., Junkermann, W., Kazantzidis, A., Kelly, P., Kift, R., Liberti, G. L., Misslbeck, M., Schallhart, B., Schreder, J., Topaloglou, C., Kazadzis, S., and Rimmer, J.: Actinic flux determination from measurements of irradiance, J. Geophys. Res., 108, doi:10.1029/2002JD003236, 2003b.

Kylling, A., Webb, A. R., Kift, R., Gobbi, G. P., Ammannato, L., Barnaba, F., Bais, A., Kazadzis, S., Wendisch, M., Jäkel, E., Schmidt, S., Kniffka, A., Thiel, S., Junkermann, W., Blumthaler, M., Silbernagl, R., Schallhart, B., Schmitt, R., Kjeldstad, B., Thorseth, T. M., Scheirer, R., and Mayer, B.: Spectral Actinic flux in the Lower Troposphere: Measurement and 1-D Simulations for Cloudless, Broken Cloud and Overcast Situations, Atmos. Chem. Phys. Discuss., 5, 1421-1467, 2005,

SRef-ID: 1680-7375/acpd/2005-5-1421.

Lacis, A. A. and Oinas, V.: A description of the correlated $k$ distribution method for modeling nongray gaseous absorption, thermal emission, and multiple scattering in vertically inhomogeneous atmospheres, J. Geophys. Res., 96, 9027-9063, 1991.

Leontyeva, E. and Stamnes, K.: Estimations of cloud optical thickness from ground-based measurements of incoming solar radiation in the Arctic, J. Climate, 7, 566-578, 1994.

Leontyeva, E., Stamnes, K., and Olseth, J. A.: Cloud optical properties at Bergen (Norway) based on the analysis of long-term solar irradiance records, Theor. Appl. Climatol., 50, 73-82, 1994.

Malicet, J., Daumont, D., Charbonnier, J., Parisse, C., Chakir, A., and Brion, J.: Ozone UV spectroscopy, II. Absorption crosssections and temperature dependence, J. Atmos. Chem., 21, 263 273, 1995.

Marquard, L. C., Wagner, T., and Platt, U.: Improved air mass factor concepts for scattered radiation differential optical absorption spectroscopy of atmospheric species, J. Geophys. Res., 105, 1315-1327, 2000.

Marshak, A., Davis, A., Wiscombe, W., and Cahalan, R.: Radiative smoothing in fractal clouds, J. Geophys. Res., 100, 26247 $26261,1995$.

Mayer, B.: I3RC phase 1 results from the MYSTIC Monte Carlo model, in Intercomparison of three-dimensional radiation codes: Abstracts of the first and second international workshops, University of Arizona Press, ISBN 0-9709609-0-5, 1999. 
Mayer, B.: I3RC phase 2 results from the MYSTIC Monte Carlo model, in: Intercomparison of three-dimensional radiation codes: Abstracts of the first and second international workshops, University of Arizona Press, ISBN 0-9709609-0-5, 2000.

Mayer, B., Seckmeyer, G., and Kylling, A.: Systematic long-term comparison of spectral UV measurements and UVSPEC modeling results, J. Geophys. Res., 102, 8755-8767, 1997.

Mayer, B., Kylling, A., Madronich, S., and Seckmeyer, G.: Enhanced absorption of UV radiation due to multiple scattering in clouds: Experimental evidence and theoretical explanation, J. Geophys. Res., 103, 31,241-31,254, 1998.

Mayer, B., Schröder, M., Preusker, R., and Schüller, L.: Remote sensing of water cloud droplet distributions using the backscatter glory: a case study, Atmos. Chem. Phys., 4, 1255-1263, 2004, SRef-ID: 1680-7324/acp/2004-4-1255.

McFarquhar, G. and Heymsfield, A.: The definition and significance of an effective radius for ice clouds, J. Atmos. Sci., 55, 2039-2052, 1998.

McKinlay, A. F. and Diffey, B. L.: A reference action spectrum for ultraviolet induced erythema in human skin, The CIE Journal, 6, 17-22, 1987.

Meloni, D., di Sarra, A., Di Iorio, J. D. T., Fiocco, G., Junkermann, W., and Pace, G.: Tropospheric aerosols in the Mediterranean: 2 Radiative effects through model simulations and measurements, J. Geophys. Res., 108 (D10), doi:10.1029/2002JD002807, 2003.

Mishchenko, M., Lacis, A., and Travis, L.: Errors induced by the neglect of polarization in radiance calculations for Rayleighscattering atmospheres, J. Quant. Spectrosc. Radiat. Transfer, 51, 491-510, 1994.

Mishchenko, M. I., Rossow, W. B., Macke, A., and Lacis, A. A.: Sensitivity of cirrus cloud albedo, bidirectional reflectance and optical thickness retrieval accuracy to ice particle shape, Geophys. Res. Lett., 101, 16973-16985, 1996.

Molina, L. T. and Molina, M. J.: Absolute absorption cross sections of ozone in the 185- to 350-nm wavelength range, J. Geophys. Res., 91, 14 501-14 508, 1986.

Nakajima, T. and Tanaka, M.: Effect of wind-generated waves on the transfer of solar radiation in the atmosphere-ocean system, J. Quant. Spectrosc. Radiat. Transfer, 29, 521-537, 1983.

Petritoli, A., Ravegnani, F., Giovanelli, G., Bortoli, D., Bonafé, U., Kostadinov, I., and Oulanosky, A.: Off-axis measurements of atmospheric trace gases by use of an airborne ultraviolet-visible spectrometer, Appl. Opt., 41, 5593-5599, 2002.

Pfeilsticker, K., Erle, F., and Platt, U.: Absorption of solar radiation by atmospheric $\mathrm{O}_{4}$, J. Atmos. Sci., 54, 934-939, 1997.

Pierluissi, J. and Peng, G.-S.: New molecular transmission band models for LOWTRAN, Optical Engineering, 24, 541-547, 1985.

Rahman, H., Pinty, B., and Verstraete, M. M.: Coupled surfaceatmosphere reflectance (CSAR) model 2. semiempirical surface model usable with NOAA advanced very high resolution radiometer data, J. Geophys. Res., 98, 20 791-20 801, 1993.

Ricchiazzi, P., Yang, S., Gautier, C., and Sowle, D.: SBDART: A research and Teaching software tool for plane-parallel radiative transfer in the Earth's atmosphere, Bulletin of the American Meteorological Society, 79, 2101-2114, 1998.

Sanders, R. W., Solomon, S., Smith, J. P., Miller, H. L., Mount, G. H., Keys, J. G., and Schmeltekopf, A. L.: Visible and nearultraviolet spectroscopy at McMurdo station, Antarctica 9. Ob- servations of OClO from April to October 1991, J. Geophys. Res., 98, 7219-7228, 1993.

Scheirer, R. and Macke, A.: Cloud inhomogeneity and broadband solar fluxes, J. Geophys. Res., 108, doi:10.1029/2002JD003321, 2003.

Schwander, H., Koepke, P., and Ruggaber, A.: Uncertainties in modeled UV irradiances due to limited accuracy and availability of input data, J. Geophys. Res., 102, 9419-9429, 1997.

Shetter, R. E., Junkermann, W., Swartz, W. H., Frost, G. J., Crawford, J. H., Lefer, B. L., Barrick, J. D., Hall, S. R., Hofzumahaus, A., Bais, A., Calvert, J. G., Cantrell, C. A., Madronich, S., Müller, M., Kraus, A., Monks, P. S., Edwards, G. D., McKenzie, R., Johnston, P., Schmitt, R., Griffioen, E., Krol, M., Kylling, A., Dickerson, R. R., Lloyd, S. A., Martin, T., Gardiner, B., Mayer, B., Pfister, G., Röth, E. P., Koepke, P., Ruggaber, A., Schwander, H., and van Weele, M.: Photolysis frequency of NO2: Measurement and modeling during the International Photolysis Frequency Measurement and Modeling Intercomparison (IPMMI), J. Geophys. Res., 108, doi:10.1029/2002JD002932, 2003.

Shettle, E. P.: Models of aerosols, clouds and precipitation for atmospheric propagation studies, paper presented at Conference on Atmospheric Propagation in the UV, Visible, IR and MM-Region and Related System Aspects, NATO Adv. Group for Aerosp. Res. and Dev., Copenhagen, 1989.

Sobolev, V.: Light Scattering in Planetary Atmospheres, Pergamon Press, Oxford, New York, Toronto, Sydney, Braunschweig, 1975.

Solomon, S., Schmeltekopf, A. L., and Sanders, R. W.: On the interpretation of zenith sky absorption measurements, J. Geophys. Res., 92, 8311-8319, 1987.

Stamnes, K., Tsay, S., Wiscombe, W., and Jayaweera, K.: A numerically stable algorithm for discrete-ordinate-method radiative transfer in multiple scattering and emitting layered media, Appl. Opt., 27, 2502-2509, 1988.

Stamnes, K., Slusser, J., and Bowen, M.: Derivation of Total Ozone Abundance and Cloud Effects from Spectral Irradiance Measurements, Appl. Opt., 30, 4418-4426, 1991.

Stamnes, K., Tsay, S.-C., Wiscombe, W., and Laszlo, I.: DISORT, a General-Purpose Fortran Program for Discrete-Ordinate-Method Radiative Transfer in Scattering and Emitting Layered Media: Documentation of Methodology, Tech. rep., Dept. of Physics and Engineering Physics, Stevens Institute of Technology, Hoboken, NJ 07030, 2000.

Stephens, G. L., Tsay, S.-C., Stackhouse Jr., P. W., and Flatau, P. J.: The relevance of the microphysical and radiative properties of cirrus clouds to climate and climatic feedback, J. Atmos. Sci., 47, 1742-1753, 1990.

Thomas, G. and Stamnes, K.: Radiative transfer in the Atmosphere and Ocean, Cambridge University Press, 1999.

Van Weele, M., Martin, T. J., Blumthaler, M., Brogniez, C., den Onter, P. N., Engelsen, O., Lenoble, J., Mayer, B., Pfister, G., Ruggaber, A., Walravens, B., Weihs, P., Gardiner, P. G., Gillotay, D., Haferl, D., Kylling, A., Seckmeyer, G., and Wauben, W. M. F.: From model intercomparison towards benchmark UV spectra for six real atmospheric cases, J. Geophys. Res., 105, 4916-4925, 2000.

Vermote, E. F., Tanré, D., Deuzé, J. L., Herman, M., and Mocrette, J.-J.: Second simulation of the satellite signal in the solar spectrum, 6S: and overview, IEEE Transactions on Geoscience and Remote Sensing, 35, 675-686, 1997. 
Wahner, A., Tyndall, G. S., and Ravishankara, A. R.: Absorption cross sections for $\mathrm{OClO}$ as a function of temperature in the wavelength range 240-480 nm, J. Phys. Chem., 91, 2734-2738, 1987.

Wahner, A., Ravishankara, A. R., Sander, S. P., and Friedl, R. R.: Absorption cross-section of $\mathrm{BrO}$ between 312 and $385 \mathrm{~nm}$ at 298 and 223 K, Chem. Phys. Lett., 152, 507-512, 1988.

Webb, A. R., Bais, A. F., Blumthaler, M., Gobbi, G.-P., Kylling, A., Schmitt, R., Thiel, S., Barnaba, F., Danielsen, T., Junkermann, W., Kazantzidis, A., Kelly, P., Kift, R., Liberti, G. L., Misslbeck, M., Schallhart, B., Schreder, J., and Topaloglou, C.: Measuring spectral actinic flux and irradiance: Experimental results from the ADMIRA (Actinic Flux Determination from Measurements of Irradiance), J. Atm. Ocean Technol., 19, 1049-1062, 2002.

Weihs, P. and Webb, A. R.: Accuracy of spectral UV model calculations, 1, Consideration of uncertainties in input parameters, J. Geophys. Res., 102, 1541-1550, 1997.

Wendisch, M. and Mayer, B.: Vertical distribution of spectral solar irradiance in the cloudless sky: A case study, Geophys. Res. Lett., 30 (4), 1183, doi:10.1029/2002GL016529, 2003.

Wiscombe, W. J. and Evans, J. W.: Exponential-sum fitting of radiative transmission functions, J. Chem. Phys., 24, 416-444, 1977.
Wiscombe, W. J. and Warren, S. G.: A model for the spectral albedo of snow, I, Pure snow, J. Atmos. Sci., 37, 2712-2733, 1980.

Wittrock, F., Oetjen, H., Richter, A., Fietkau, S., Medeke, T., Rozanov, A., and Burrows, J. P.: MAX-DOAS measurements of atmospheric trace gases in Ny-Ålesund - Radiative transfer studies and their application, Atmos. Chem. Phys., 4, 955-966, 2004,

SRef-ID: 1680-7324/acp/2004-4-955.

Woods, T. N., Prinz, D. K., Rottmann, G. J., London, J., Crane, P. C., Cebula, R. P., Hilsenrath, E., Brueckner, G. E., Andrews, M. D., White, O. R., VanHoosier, M. E., Floyd, L. E., Herring, L. C., Knapp, B. G., Pankrantz, C. K., and Reiser, P. A.: Validation of the UARS solar ultraviolet irradiances: Comparison with the Atlas 1 and 2 measurements, J. Geophys. Res., 101, 95419569, 1996.

Yang, P., Liou, K., Wyser, K., and Mitchell, D.: Parameterization of the scattering and absorption properties of individual ice crystals, J. Geophys. Res., 105, 4699-4718, 2000. 